\title{
Multiscale micromechanical analysis of alkali-activated fly ash-slag paste
}

\author{
Guohao Fang, Mingzhong Zhang* \\ Department of Civil, Environmental and Geomatic Engineering, University College London, London WC1E 6BT, UK
}

\section{A R T I C L E I N F O}

\section{Keywords:}

Alkali-activated concrete

Microstructure

Elastic modulus

Hardness

Nanoindentation

\begin{abstract}
A B S T R A C T
Current demand for highly sustainable concrete, e.g. alkali-activated fly ash-slag (AAFS) concrete, urges understanding the links between microstructure and micromechanical properties of this binder. This paper presents a systematic investigation into the microstructure and micromechanical properties of AAFS paste from nanoscale to micro-scale. Nanoindentation was used to evaluate the micromechanical properties, while the microstructure was characterised using ${ }^{29} \mathrm{Si}$ nuclear magnetic resonance, Fourier transform infrared spectroscopy, backscattered electron microscopy, and mercury intrusion porosimetry. The results indicate that N-A-S-H gels have a relatively low elastic modulus due to their high level of structural disorder and gel porosity, while the CA-S-H gels and N-C-A-S-H gels with a low level of structural disorder and gel porosity have a relatively high elastic modulus. The elasticity of reaction products and their relative volumetric proportions mainly determine the macroscopic elasticity of AAFS paste, while the porosity and pore size distribution primarily condition its macroscopic strength.
\end{abstract}

\section{Introduction}

Alkali-activated materials (AAM), manufactured through the reaction of alkaline activator with aluminosilicate precursors, have been regarded as an environmentally friendly alternative to Portland cement (PC) because of the low $\mathrm{CO}_{2}$ emission and the low consumption of natural resources [1-3]. Although AAM exhibits comparable engineering properties to $\mathrm{PC}$, some critical issues have emerged in the commonly used AAM, e.g. alkali-activated fly ash (AAF) and alkaliactivated slag (AAS). For instance, AAF requires rigorous curing conditions with elevated temperature $\left(60-85{ }^{\circ} \mathrm{C}\right)$ to gain early-age strength, whereas AAS has some drawbacks including poor workability and quick setting [4-6]. To conquer these limitations, recent developments in the field of AAM have led to an increasing interest in the blended AAM, called alkali-activated fly ash-slag (AAFS), which can achieve the desired engineering properties under ambient curing conditions [6-8].

Until now, most studies of AAFS have concentrated on the chemistry, microstructure, and macro-scale properties, e.g. mechanical properties and durability. It was reported that the chemical reaction of AAFS would lead to the generation of tetracoordinate $\mathrm{Al}$ charge-balanced by $\mathrm{Na}$ and reaction products in the $\mathrm{Na}_{2} \mathrm{O}-\mathrm{CaO}-\mathrm{Al}_{2} \mathrm{O}_{3}-\mathrm{SiO}_{2}$ system, containing N-A-S-H gels, C-A-S-H gels and N-C-A-S-H gels [9]. The N-A-S-H type gel is mainly generated from the reaction of fly ash, which has a stable three-dimensional structure, enhancing the long- term durability $[10,11]$. The C-A-S-H type gel produced from the activation of slag is expected to promote the development of mechanical strength [12]. The N-C-A-S-H type gel is generated through the incorporation of Ca released from slag into the N-A-S-H type gel, which has comparable structural features to C-A-S-H type gel [9]. Additionally, the chemical interaction between fly ash and slag takes place during the reaction of AAFS $[7,13,14]$. The interaction mechanism can be mainly demonstrated as: (1) modifying the nanostructure and chemical composition of different reaction products, (2) triggering or suppressing the formation of crystalline phases within reaction products, and (3) homogenising the chemical composition and microstructure [13]. Furthermore, the microstructure and mechanical properties of AAFS are strongly dependent on various factors including the relative amount of fly ash and slag [15,16], and activator type and concentration [17-19]. The AAFS mixture with a high slag content shows a high reaction rate and a dense microstructure due to the soluble Ca from slag, which would promote the generation of C-A-S-H gels and result in a quicker setting as well as a higher strength than the mixture with a low slag content $[20,21]$. Nevertheless, more crosslinked binders with durable solid microstructure can be obtained in the mixture with a high fly ash content, attributing to the formation of N-A$\mathrm{S}-\mathrm{H}$ gels [9]. Regarding the effect of activator types, it was found that the AAFS mixture activated by a blend of sodium hydroxide ( $\mathrm{SH}$ ) solution and sodium silicate (SS) solution achieves a higher strength than that activated by SH or SS solution alone [19].

\footnotetext{
* Corresponding author.

E-mail address: mingzhong.zhang@ucl.ac.uk (M. Zhang).
} 
Level 0: Solid gel particle
Level I: Gel matrix
Level II: Paste

$1 \mathrm{~nm} \sim 10 \mathrm{~nm}$

$10 \mathrm{~nm} \sim 1 \mu \mathrm{m}$

$1 \mu \mathrm{m} \sim 100 \mu \mathrm{m}$

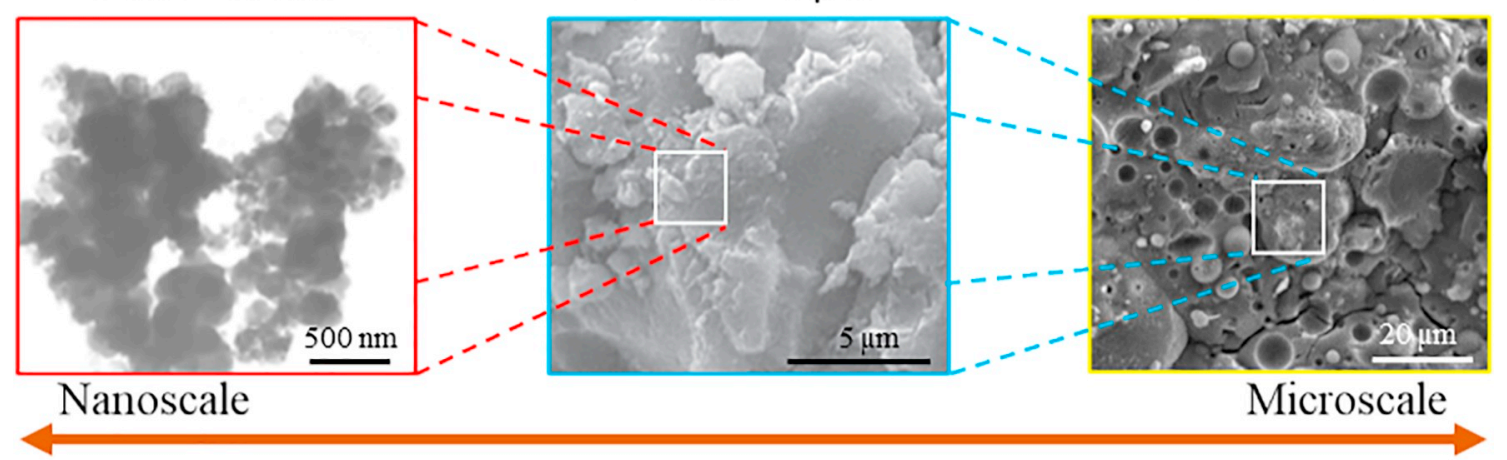

Micromechanical properties

Fig. 1. Schematic diagram of multiscale micromechanical analysis of AAFS paste (TEM/SEM images obtained from [20,36]).

The microstructure evolution and development of mechanical properties of AAFS mixtures at micro-scale and macro-scale are highly related to the reaction kinetics and formation of reaction products [6]. A good understanding of these relations would bring a deeper insight into the formation and development of microstructure and micromechanical properties, e.g. elastic modulus and hardness [22,23]. The elastic modulus is related to stiffness, while the hardness is associated with mechanical strength [24]. Therefore, it is vital to investigate the relationship between microstructure and micromechanical properties in AAFS paste.

The micromechanical properties of component phases in PC paste have been usually explored with the assistance of nanoindentation technique [25-27]. Two distinct types of C-S-H gels, i.e. a high-density type and a low-density type, were demonstrated from a micromechanical point of view [28]. It was reported that the micromechanical properties of C-S-H gels are intrinsic material properties and would not be affected by the PC mix proportions. The volume fraction of these two C-S-H gels dominates the macroscopic mechanical properties of PC mixtures [26]. Recently, several attempts have been made to investigate the micromechanical properties of AAF and AAS. Three distinct phases including reaction products, residual fly ash particles and pores can be identified in AAF. The residual fly ash particles have the highest elastic modulus and hardness, followed by reaction products (N-A-S-H gels) and pores [29-32]. The elastic modulus of N-A-S-H gels in AAF is stable at around 16- $18 \mathrm{GPa}$, independent of the curing procedure and the molar ratio of alkaline activator [29-31]. In regard to AAS, the unreacted slag exhibits the highest hardness and elastic modulus, attributing to the crystalline impurities [12,23]. The hardness and elastic modulus of reaction products in SS-activated slag are $2.5 \mathrm{GPa}$ and $30 \mathrm{GPa}$, respectively, which are higher than that in $\mathrm{SH}$ activated slag with hardness of $1 \mathrm{GPa}$ and elastic modulus of $25 \mathrm{GPa}$ [23]. The micromechanical properties of reaction products in SH-activated slag are dependent on the activator molarity, while those in SSactivated slag are slightly improved with increasing silica modulus [23].

Although these studies have provided some valuable information on the mechanical properties of sole AAM, the existing knowledge is often limited to a micromechanics viewpoint and the relationships between microstructure and micromechanical properties have been rarely addressed in previous studies. Characterising the microstructure and micromechanical properties at multiscale from nano-scale to micro-scale would enable us to build a link between chemistry and properties, bringing new insights into the development of mechanical properties of AAM. Moreover, the existing research on micromechanical properties of the blended AAM (i.e. AAFS) is limited to the analysis of carbonation effects on its elastic modulus [33]. Up to now, a systematic understanding of the microstructure and micromechanical properties of individual phases within AAFS and the corresponding relationship with the macro-scale mechanical properties is still lacking.

To fill in the gap of knowledge, this paper aims at investigating the microstructure and micromechanical properties of AAFS paste at multiple scales from nano-scale to micro-scale. The features of AAFS paste are clarified according to three multiple length scales, including Level 0 (solid gel particle: $1 \mathrm{~nm} \sim 10 \mathrm{~nm}$ ), Level I (gel matrix: $10 \mathrm{~nm} \sim 1 \mu \mathrm{m}$ ), and Level II (paste: $1 \mu \mathrm{m} \sim 100 \mu \mathrm{m}$ ). The microstructure from Level 0 to Level II is systematically characterised using ${ }^{29} \mathrm{Si}$ nuclear magnetic resonance (NMR), Fourier transform infrared spectroscopy (FTIR), backscattered electron microscopy (BSEM), and mercury intrusion porosimetry (MIP). The micromechanical properties of gel matrix (Level I) including the elastic modulus and hardness are measured by means of nanoindentation. Finally, the effective mechanical properties of AAFS paste (Level II) are determined based on the self-consistent continuum micromechanics model.

\section{Multiscale micromechanical analysis of AAFS paste}

From the chemical reaction that occurs in AAFS paste, it is readily understood that the hardened AAFS paste is a multiphase composite material consisting of reaction products, unreacted particles and pores. The most prominent feature of this heterogeneous material is its widescale microstructure from nano-scale to micro-scale. To make a comprehensive characterisation of micromechanical properties, it is vital to separate the different microstructural features based on their length scales.

\subsection{Multiscale characterisation of AAFS paste}

Informed by the multiscale structure of AAFS paste and the micromechanical multiscale model of cement paste and AAM developed by other researchers [22,26,34,35], a schematic diagram for the multiscale micromechanical analysis of AAFS paste is shown in Fig. 1, where the transmission electron microscope (TEM) and scanning electron microscope (SEM) images were obtained from the literature [20,36]. The multiscale features of AAFS paste were identified based on three multiple length scales: Level 0, Level I, and Level II.

\subsubsection{Level $O(L=1 \mathrm{~nm} \sim 10 \mathrm{~nm})$ : Solid gel particle}

Level 0 defines the length scale referred to the solid gel particles 
which are the elementary components of the crystal or amorphous structures of the phases [37]. In AAFS, alkali aluminosilicate (N-A-S-H) gel and calcium aluminosilicate hydrate (C-A-S-H) gel are the two main reaction products [9]. The N-A-S-H gel with a highly cross-linked disordered structure is generated from the reaction of fly ash, which has a three-dimensional framework of $\mathrm{SiO}_{4}$ and $\mathrm{AlO}_{4}$ tetrahedra linked through shared O atoms [38]. According to NMR analysis, N-A-S-H gel has considerable content of $\mathrm{Q}^{4}(\mathrm{mAl})$ sites, where the distribution of $\mathrm{m}$ values depends on the $\mathrm{Si} / \mathrm{Al}$ ratio of the reactive component of fly ash and the content of Si supplied from the activator [39]. It was found that the N-A-S-H gel structure is closely related to a disordered zeolite-like structure, which has a length scale of $\sim 8-10 \mathrm{~nm}$ [40].

Regarding C-A-S-H gel, it consists of tetrahedrally coordinated silicate chains with a dreierkette structure, where each chain is composed of $(3 n-1)$ tetrahedra, similar to the C-S-H gel in PC paste [41]. Nevertheless, the chain length of C-A-S-H gel (up to 13 tetrahedra) is longer than that of C-S-H gel (three to five tetrahedra) [12]. It was reported that the structure of C-A-S-H gel is indicative of the co-existence of tobermorite $1.1 \mathrm{~nm}$ and tobermorite $1.4 \mathrm{~nm}$ [12]. Moreover, the hybrid solid gel called N-C-A-S-H can also be identified, as part of $\mathrm{Na}$ in N-A-S-H gel is replaced by the Ca released from slag [9]. The Casubstituted N-A-S-H gel (N-C-A-S-H gel) may have a mineral feature between N-A-S-H gel and C-A-S-H gel, which retains the original 3D aluminosilicate framework structure but tends to have a similar composition with C-A-S-H gel [36].

Furthermore, the secondary products such as crystalline zeolites and hydrotalcite phases are also generated with the formation of main reaction products [39]. Zeolites are crystalline hydrated aluminosilicates, consisting of $\mathrm{SiO}_{4}$ and $\mathrm{AlO}_{4}$ tetrahedra linked through $\mathrm{O}$ atom [42], while the hydrotalcite phase exhibits a layered double hydroxide structure, where the interlayer region contains $\mathrm{CO}_{3}{ }^{2-}$ ions and water molecules [43]. However, it should be noted that the content of crystalline zeolites and hydrotalcite phases is extremely low in AAFS (normally $<5 \%$ by mass of binder) $[13,44]$. For instance, the precipitation of zeolite-type phases in AAFS is suppressed due to the presence of slag, while the Ca released from slag would react with N-A-S-H gel to form N-C-A-S-H gel, leading to a heterogeneous chemical distribution and inhibiting zeolite crystallization [13]. In comparison, the main reaction products (i.e. N-A-S-H gel, N-C-A-S-H gel and C-A-S-H gel) dominate the AAFS paste (normally over $90 \%$ by mass of binder) [13]. The macroscopic mechanical properties of AAFS paste are expected to be governed by the micromechanical properties of main reaction products. Therefore, the micromechanical properties of these main reaction products are mainly discussed here.

The microstructural analysis above indicates that the size of solid gel particles of main reaction products is in the range of $1 \mathrm{~nm} \sim 10 \mathrm{~nm}$, which is therefore considered as the characteristic size of Level 0 in this study.

\subsubsection{Level $I(L=10 \mathrm{~nm} \sim 1 \mu \mathrm{m})$ : Gel matrix}

Level I represents the length scale corresponding to the generation of gel matrix which is agglomerated by the solid gel particles (with length scale of $1 \mathrm{~nm} \sim 10 \mathrm{~nm}$ ) along with the presence of gel pores with the size ranging from $2 \mathrm{~nm}$ to $50 \mathrm{~nm}$. According to the authors' previous study [45] and literature [46], the gel pores formed in interstices between solid gel particles can be identified in AAFS paste. During the alkaline activation of AAFS, the solid gel particles would appear and aggregate into clusters with the presence of gel pores. The agglomeration of these solid gel particles would create the gel-like matrix with a scale of tens to hundreds nanometre [22]. Accordingly, the length scale of Level I is set in the range of $10 \mathrm{~nm} \sim 1 \mu \mathrm{m}$.

\subsubsection{Level II $(L=1 \mu \mathrm{m} \sim 100 \mu \mathrm{m})$ : Paste}

Level II denotes the length scale at paste level, which correlates to the AAFS paste consisting of the gel matrix from Level I (with length scale of $10 \mathrm{~nm} \sim 1 \mu \mathrm{m}$ ), capillary pores and unreacted fly ash and slag particles. The capillary pores remain in the originally liquid-filled spaces with the size ranging from $10 \mathrm{~nm}$ to $1 \mu \mathrm{m}$ in AAFS paste, as reported in the authors' previous research [45] and literature [46]. In addition, it was observed that the particle sizes of fly ash and slag cover the range between $1 \mu \mathrm{m}$ and $100 \mu \mathrm{m}$ [47]. Therefore, the length scale of Level II is set in the range of $1-100 \mu \mathrm{m}$ considering the microstructural features at this level.

\subsection{Microstructure-mechanical property relationships in AAFS paste at various length scales}

The information about micromechanical properties would help us establish the links between microstructure and mechanical properties, offering a deeper insight into the influence of different phases on overall mechanical properties of AAFS paste $[22,48]$. To date, the smallest material length scale that can be accessed by nanoindentation test is gel matrix at Level I $[28,49]$. By assuming that each nanoindentation test serves for a single phase in the material, the effective elastic modulus of AAFS paste can be estimated using the self-consistent continuum micromechanics models [50]. It was indicated that the predicted effective elastic modulus agrees well with the macroscopic elastic modulus obtained from experiments, e.g. ultrasonic pulse velocity and resonant frequency tests [51,52]. This suggests that the micromechanical properties in relation to the length scale of level I (gel matrix) can be utilized to evaluate the effective properties at paste level (Level II) [53]. Moreover, the micromechanical properties of gel matrix at level I can also be downscaled to understand the chemical and physical characteristics of solid gel particles at level 0 [22].

\section{Experimental program}

\subsection{Raw materials}

In this study, low-calcium fly ash and ground granulated blast-furnace slag were used as precursors $(\mathrm{P})$, the chemical composition and the average particle size of which are presented in Table 1 . Based on the authors' previous study [21], a mixture of SH solution with molarity of 10 and SS solution with modulus (molar ratio of $\left[\mathrm{SiO}_{2}\right] /\left[\mathrm{Na}_{2} \mathrm{O}\right]$ ) of 2.0 was used as the alkaline activator (AL) for AAFS mixtures which can meet the performance criteria of workability [54], setting time [55] and compressive strength [56]. The SH solution consists of $30.55 \mathrm{wt} \%$ $\mathrm{NaOH}$ and $69.45 \mathrm{wt} \% \mathrm{H}_{2} \mathrm{O}$, while the SS solution is composed of $30.71 \mathrm{wt} \% \mathrm{SiO}_{2}, 15.36 \mathrm{wt} \% \mathrm{Na}_{2} \mathrm{O}$ and $53.93 \mathrm{wt} \% \mathrm{H}_{2} \mathrm{O}$. To adjust the workability of AAFS paste, the modified polycarboxylate-based superplasticizer (SP) (Sika ${ }^{\circledR}$ ViscoFlow ${ }^{\circledR} 2000$, Sika, UK) was applied as the admixture, which can help effectively increase the workability of AAFS

Table 1

Chemical composition and particle size of fly ash (FA) and ground granulated blast-furnace slag (GGBS).

\begin{tabular}{|c|c|c|c|c|c|c|c|c|c|c|c|}
\hline & \multicolumn{10}{|c|}{ Oxide (wt\%) } & Average particle size $(\mu \mathrm{m})$ \\
\hline FA & 55.76 & 30.22 & 3.56 & 2.33 & 0.91 & 0.46 & 1.72 & 0.40 & 0.79 & 0.27 & 19.06 \\
\hline
\end{tabular}


Table 2

Specific density $\left(\mathrm{g} / \mathrm{cm}^{3}\right)$ of different ingredients in AAFS paste.

\begin{tabular}{llllll}
\hline & FA & GGBS & SS & SH & SPs \\
\hline Specific density & 2.25 & 2.90 & 1.38 & 1.21 & 1.08 \\
\hline
\end{tabular}

Table 3

Mixture quantity of AAFS paste.

\begin{tabular}{lllllll}
\hline & FA & GGBS & SS & SH & SPs & \multicolumn{1}{c}{ Total } \\
\hline Weight $(\mathrm{g})$ & 300 & 100 & 120 & 60 & 4 & 584 \\
Volume $\left(\mathrm{cm}^{3}\right)$ & 133.33 & 34.48 & 86.95 & 49.59 & 3.70 & 308.05 \\
\hline
\end{tabular}

paste by around $30 \%$ with the addition of $1 \mathrm{wt} \%$ [57]. The specific densities of these raw materials are presented in Table 2.

\subsection{Mix proportion and sample preparation}

The mix proportion of AAFS paste used in this study was determined according to the authors' previous research [21] and the literature $[15,57,58]$. The replacement ratio of slag for fly ash was $25 \mathrm{wt} \%$, while the mass ratios of $\mathrm{AL} / \mathrm{P}, \mathrm{SS} / \mathrm{SH}$ and $\mathrm{SP} / \mathrm{P}$ were set as $0.45,2.0$ and 0.01 , respectively. In addition, the liquid/solid (L/S) ratio was set as 0.23 , where the liquid (L) denotes the water content in SS and SH, while the solid (S) includes the content of P and the solid content in SS and SH. Accordingly, the mixture quantity of AAFS paste was calculated as shown in Table 3. The mixtures with selected proportion can achieve a desired performance in terms of acceptable workability (i.e. minimum slump value of 90 according to [54]), suitable setting time (i.e. minimum initial setting time of 60 min according to BS EN 197-1:2011 [55]), and high compressive strength (i.e. minimum 28-d compressive strength of $35 \mathrm{MPa}$ according to BS EN 206:2013 + A1:2016 [56]).

The mixing process of AAFS paste started from the dry mixing of fly ash and slag for the first $2 \mathrm{~min}$ and continued for another $3 \mathrm{~min}$ along with the addition of alkaline solution (SS and SH) and SP. The fresh paste was then cast into the cube moulds with a size of $20 \mathrm{~mm}$. Afterwards, the moulds were put on the vibrating table for around $2 \mathrm{~min}$ and sealed by the plastic sheet for $24 \mathrm{~h}$ in room temperature $\left(20 \pm 2{ }^{\circ} \mathrm{C}\right)$. Finally, the samples were demoulded and placed in a curing room $\left(20 \pm 2{ }^{\circ} \mathrm{C}, 95 \% \mathrm{RH}\right)$ until the testing ages of $1,3,7$ and $28 \mathrm{~d}$ were achieved.

At each curing age, the samples were cut into smaller specimens with a size of $2 \times 20 \times 20 \mathrm{~mm}$ by a low-speed diamond saw. The specimens were stored in the isopropanol solution to stop the hydration of binder for $2 \mathrm{~d}$. The isopropanol solution has been demonstrated as a promising organic solvent to remove the free water inside the composite material without significant influences on its microstructure $[59,60]$. After that, the specimens were stored in the vacuum drying dish for at least $2 \mathrm{~d}$ to dry the specimen up and stop the potential carbonation.

Finally, the specimens were further prepared to fulfil the requirement of different tests. For the ${ }^{29} \mathrm{Si}$ NMR, XRD and FTIR tests, the specimens were ground into powder using agate mortar to pass through $63-\mu \mathrm{m}$ sieve. For the MIP tests, the specimens were cut into smaller pieces with a size of about $2-5 \mathrm{~mm}$. For the BSEM and nanoindentation tests, the specimens should be well-polished to provide a smooth and flat surface. More details about the sample preparation for the BSEM and nanoindentation tests can be found in the authors' previous study [61].

\subsection{Testing methods}

\subsubsection{Nanostructure characterisation of solid gel particle}

The nanostructure of solid gel particle was investigated by means of ${ }^{29} \mathrm{Si} \mathrm{NMR}$, which has been widely applied to qualitatively and quantitatively evaluate the nanostructure of AAM $[11,62,63] .{ }^{29} \mathrm{Si}$ NMR can reveal the silicate structure in binding gels, contributing to understanding the structural compositions of reaction products at nanoscale [62]. Besides, the deconvolution of the obtained ${ }^{29} \mathrm{Si}$ NMR spectra provides a possible way for the quantitative analysis, bringing further information on the nanostructure changes, chain length and elements' ratios of binding gels $[11,64]$. Here, the solid-state ${ }^{29} \mathrm{Si}$ NMR instrument (BRUKER, AVANCE 400WB, Germany) was utilized to investigate the nanostructure of solid gel particles, using the ${ }^{29} \mathrm{Si}$ resonance frequency of $79.48 \mathrm{MHz}$ and the spinning speed of $5 \mathrm{kHz}$. The ${ }^{29} \mathrm{Si}$ NMR experiments applied a pulse length of $4.97 \mu$ s and a relaxation delay of 5 s with 2048 scans.

\subsubsection{Chemical composition characterisation of gel matrix}

Since the main reaction products formed in AAFS paste belong to the amorphous phase, the chemical composition of gel matrix was characterised by means of FTIR. It was reported that the disorder phases (amorphous phases) formed in AAFS paste can be well identified by FTIR test [9]. Here, an FTIR instrument (Shimadzu, IRTracer-100, Japan) with 16 times scanning from 4000 to $400 \mathrm{~cm}^{-1}$ and a resolution of $4 \mathrm{~cm}^{-1}$ was used to characterise the gel matrices.

\subsubsection{Microstructure characterisation of AAFS paste}

BSEM test [65] and MIP test [66] were performed to investigate the composition and distribution of solid phases and the pore structure of AAFS paste, respectively. For the BSEM test, the ESEM instrument (FEI, QUANTA FEG 450, USA) was used in this study, where the working distance was set around $10 \mathrm{~mm}$, while the acceleration voltage and spot size were set as $15 \mathrm{kV}$ and $6.0 \mathrm{~nm}$, respectively. The used magnifications include $250 \times$ and $1000 \times$ and the image size was $1024 \times 884$ pixels. Regarding the MIP test, the MIP instrument (Micromeritics Instrument Ltd., AutoPore IV 9500, USA) was used, where the pressure between 0 and $420 \mathrm{MPa}$ was applied. The surface tension of mercury was set as $0.485 \mathrm{~N} / \mathrm{m}$, while the contact angle between mercury and pore surface was set as $130^{\circ}$ according to previous studies $[67,68]$.

\subsubsection{Micromechanical property tests}

The surface topographic of polished specimens was measured using atomic force microscopy (AFM) (Bruker, Dimension ICON, USA), in order to make sure that the polished samples can fulfil the requirement of nanoindentation test. The specimens were scanned under the Peakforce mode to collect a topographic map. The scanning was operated with an engage setpoint of $0.85 \mathrm{~V}$, a peak force amplitude of $300 \mathrm{mV}$ and a scan rate of $1.0 \mathrm{~Hz}$. The scanning size at the interface was $50 \times 50 \mu \mathrm{m}$. The digital analysis was then conducted on each image to obtain the roughness value. Here the root-mean-squared roughness number (RMS) was used to describe the surface roughness [24,69]. The RMS roughness of AAFS samples at different curing ages was calculated and presented in Table 4.

The micromechanical properties of AAFS paste were characterised with the help of nanoindentation, which is regarded as an effective method to measure the local elastic modulus and hardness [70]. In this study, the nanoindentation test instrument with a Berkovich indenter tip (BRUKER, Hysitron TI 950, Germany) was used, which can achieve a load resolution of $1 \mathrm{nN}$ and a displacement resolution of $0.04 \mathrm{~nm}$. The nanoindentation test started from the loading increased at a constant rate of $400 \mu \mathrm{N} / \mathrm{s}$ until the maximum load of $2 \mathrm{mN}$ is reached. The maximum load was set based on the average indentation depth of $300 \mathrm{~nm}$. And then, the load at this maximum level was held for $2 \mathrm{~s}$,

Table 4

RMS roughness of AAFS paste at different curing ages.

\begin{tabular}{lllll}
\hline & 1-d & 3-d & 7-d & 28-d \\
\hline RMS roughness (nm) & 119 & 165 & 95.6 & 98.8 \\
\hline
\end{tabular}




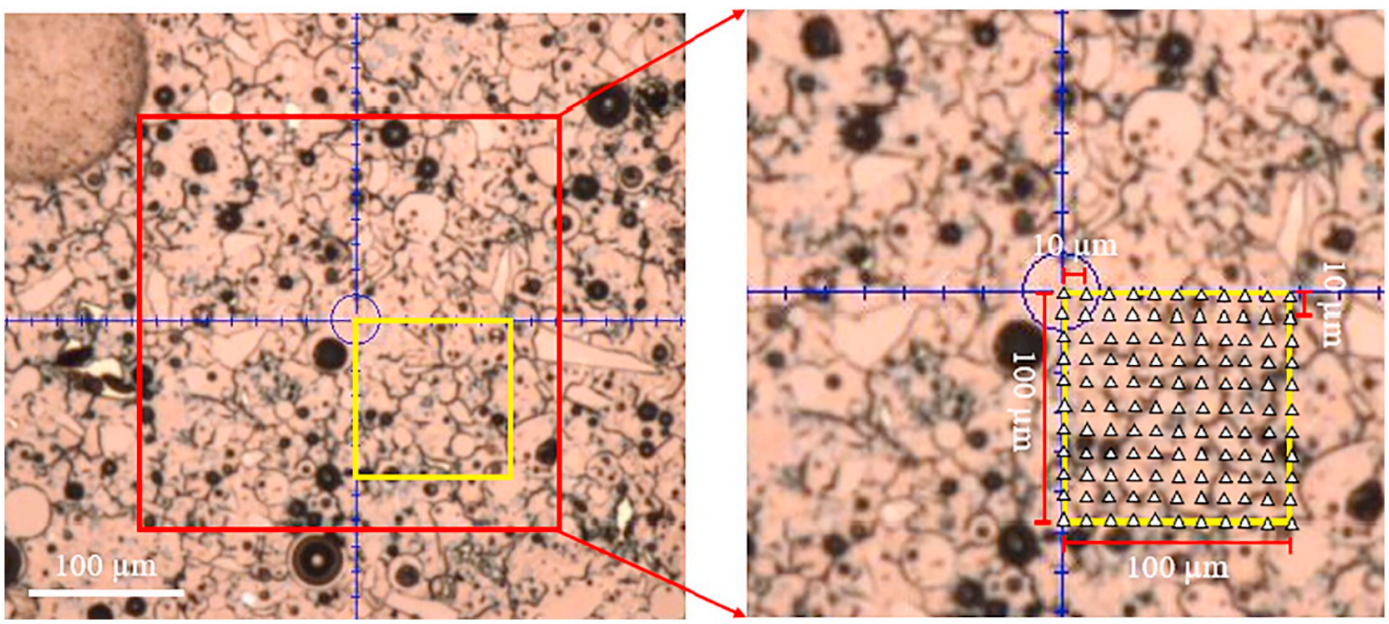

Fig. 2. Schematic illustration of the indented area.

followed by unloading at a constant rate of $400 \mu \mathrm{N} / \mathrm{s}$. Here, the average indentation depth $(300 \mathrm{~nm})$ was 2 times greater than the surface roughness (around $100 \mathrm{~nm}$ ), which allows avoiding the effect of roughness on the measured properties (see Table 4).

The classical nanoindentation mode and grid nanoindentation mode were applied in this work. Regarding the classical nanoindentation, for each phase including unreacted fly ash, unreacted slag and reaction products, 10 indentation tests were conducted on different locations in each sample. In terms of grid nanoindentation, for each sample, 121 indentations were given on a grid of $100 \times 100 \mu \mathrm{m}$ with $10 \mu \mathrm{m}$ space between indents. Such space was 33 times larger than the indentation depth, which should be sufficient to avoid the effects of interaction microvolume during nanoindentation tests (normally about 3-5 times the indentation depth [71]). The representative grid testing area is shown in Fig. 2.

After testing, the load-displacement curves can be obtained. In addition, two basic mechanical properties, i.e. indentation modulus $(M)$ and hardness $(H)$, can be calculated based on the load-displacement curves [72,73], where $M$ represents the elastic properties of the tested material and indenter tip. The elastic modulus $(E)$ of the tested material can be calculated as follows [74]:

$E=\left(1-v^{2}\right) \cdot\left[\frac{1}{M}-\frac{\left(1-v_{\text {tip }}^{2}\right)}{E_{\text {tip }}}\right]^{-1}$

where $E_{\text {tip }}$ denotes the elastic modulus of indenter tip, $v$ is the Poisson's ratio of the tested material, and $v_{\text {tip }}$ is the Poisson's ratio of the indenter tip.

The values of $E_{\text {tip }}$ and $v_{\text {tip }}$ of indenter tip used here are $1140 \mathrm{GPa}$ and 0.07 , respectively. The value of $v$ for alkali-activated materials is normally in the range of 0.13 and $0.26[75,76]$. Since the change of $v$ from 0.13 to 0.26 would not introduce significant errors to the results according to Eq. (1), $v$ was set as 0.2 in this study. Additionally, the bulk modulus $(K)$ and shear modulus $(G)$ can be calculated as: $K=\frac{E}{3(1-2 v)}$ and $G=\frac{E}{2(1+v)}$, respectively.

\section{Results}

\subsection{Nanostructure of solid gel particle}

$\mathrm{Q}^{\mathrm{n}}(\mathrm{mAl})$ structural units are commonly used in ${ }^{29} \mathrm{Si}$ NMR spectra to identify the chemical environment of silicon tetrahedra of phases, where $n$ represents the number of oxygen bridges between each silicon tetrahedral unit and other silicon atoms, and $m$ is the number of aluminium tetrahedra taking place in bridging position [77]. As shown in Fig. 3, $Q^{0}$ unit represents the isolated silicon tetrahedron; $Q^{1}$ unit describes the silicon tetrahedron that only connects with another silicon tetrahedron; while $\mathrm{Q}^{2}$ unit stands for the silicon tetrahedron connecting to other two silicon tetrahedrons; $\mathrm{Q}^{3}$ unit denotes a silicon tetrahedron that connects with other three tetrahedrons, having a chain branching, double-chain polymerisation, or a layered structure; and $Q^{4}$ unit represents a silicon tetrahedron linking with other three tetrahedrons to form a three-dimensional network [78]. The obtained spectra can be deconvolved to make a quantitative analysis and explore the changes in silicate structure of different reaction products [62]. Herein, the overlapped peaks were deconvolved using a statistical analysis software called "PeakFit", where the Gaussian line model was applied.

The ${ }^{29} \mathrm{Si}$ NMR spectra of raw materials, i.e. fly ash and slag, were presented and deconvolved in Fig. 4a and b. The spectrum of fly ash shows an overlapped peak between -80 and $-120 \mathrm{ppm}$, indicating the existence of different $Q^{4}$ structures (see Fig. 4a). The overlapped peak can be deconvolved into five $\mathrm{Q}^{4}$ structures of $\mathrm{Q}^{4}(4 \mathrm{Al})(-87 \mathrm{ppm})$, $\mathrm{Q}^{4}(3 \mathrm{Al})(-95 \mathrm{ppm}), \mathrm{Q}^{4}(2 \mathrm{Al})(-103 \mathrm{ppm}), \mathrm{Q}^{4}(1 \mathrm{Al})(-110 \mathrm{ppm})$, and $\mathrm{Q}^{4}(0 \mathrm{Al})(-116 \mathrm{ppm})$. Different types of $\mathrm{Q}^{4}$ structures can be attributed to the presence of amorphous and crystalline phases [79]. Regarding slag, only a broad peak between -55 and -95 ppm can be found, centred at around $-75 \mathrm{ppm}$, which corresponds to the $\mathrm{Q}^{0}$ and $\mathrm{Q}^{1}$ sites, implying the presence of high proportion of amorphous phase and low content of crystalline phase (see Fig. 4b) [62].

Fig. 4c presents the ${ }^{29} \mathrm{Si}$ NMR spectrum of AAFS paste, which was deconvolved into serval peaks based on the information available for AAFS $[9,11,62]$, and the peak positions were held constant for all mixtures. It should be noted that it is unlikely to separate the remnant precursors (i.e. fly ash and slag) and reaction products in ${ }^{29} \mathrm{Si} \mathrm{NMR}$ spectrum due to the presence of vitreous phases within precursors which share the similar $Q^{n}(m A l)$ structural units with reaction products. Nevertheless, since the $\mathrm{Q}$ sites from the original precursors can be assumed to be unchanged, the relative changes of $Q$ sites at different curing ages can be considered as the development of reaction products. Using this observation, it is possible to characterise the evolution of reaction products in the ${ }^{29} \mathrm{Si}$ NMR spectrum. The deconvolution results and relative quantification of all mixtures are summarised in Table 5. The Al/Si ratios of N-A-S-H gels, N-C-A-S-H gels and C-A-S-H gels were also calculated to evaluate the change in chemical composition of solid gel particles $[62,80]$. Here, the AAFS mixture cured for $28 \mathrm{~d}$ is taken as an example to identify different $\mathrm{Q}^{\mathrm{n}}(\mathrm{mAl})$ structural units in AAFS paste. The spectrum exhibits a broad peak between -60 and $-90 \mathrm{ppm}$, representing a large amount of $Q^{0}, Q^{1}$ and $Q^{2}$ sites from the initial slag and the depolymerised reaction products. The wide coverage area with a range of -90 and $-120 \mathrm{ppm}$ corresponds to the $\mathrm{Q}^{4}$ sites, which are mainly obtained from fly ash and its highly polymerised reaction products. More specifically, The peak at $-74 \mathrm{ppm}$ is associated with the $\mathrm{Q}^{0}$ 


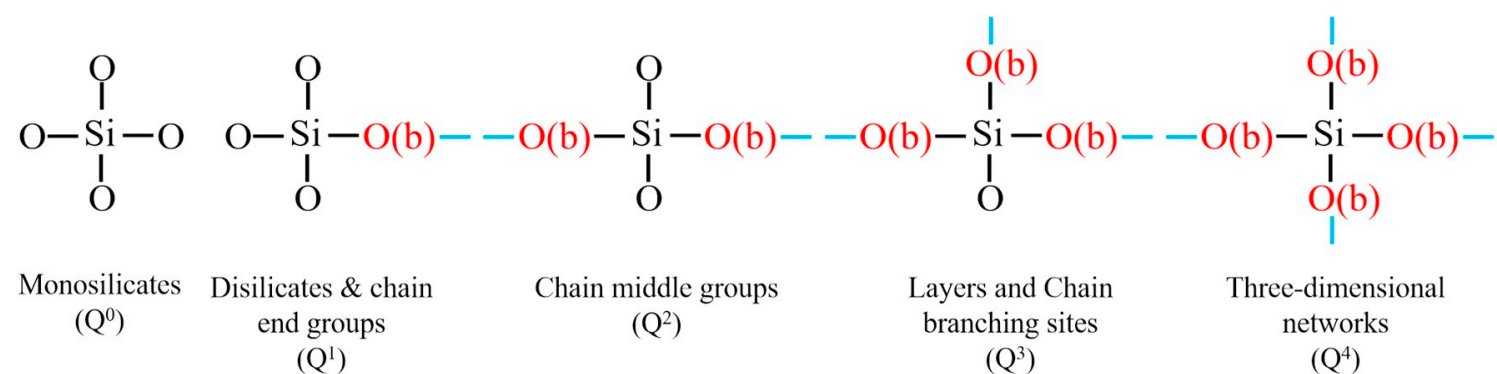

Fig. 3. Structural schematic diagram of $Q^{\mathrm{n}}$ in solid silicates $(\mathrm{O}(\mathrm{b})$ represents bridging oxygen).

site, indicating the presence of unaltered crystalline phases (i.e. merwinite and melilite) in the original slag $[62,81,82]$. The $\mathrm{Q}^{1}$ site located at $-77 \mathrm{ppm}$ is assigned to the end of chain silicate tetrahedral within CA-S-H gels [62]. The $\mathrm{Q}^{2}(1 \mathrm{Al})$ site located at $-83 \mathrm{ppm}$ is corresponding to the middle-of-chain silicate within C-A-S-H gels [83]. The peak at $-88 \mathrm{ppm}$ refers to the $\mathrm{Q}^{3}(1 \mathrm{Al})$ and $\mathrm{Q}^{4}(4 \mathrm{Al})$ sites due to the overlapping of resonances within this region [84], which is assigned to the coexistence of C-A-S-H gels and N-A-S-H gels, presenting as a highly crosslinked N-C-A-S-H gel $[9,84]$. Normally, $\mathrm{Q}^{3}(1 \mathrm{Al})$ site is related to the alumina-modified C-S-H gels (C-A-S-H gels) [85], while $\mathrm{Q}^{4}(4 \mathrm{Al})$ site is assigned to the Al-rich N-A-S-H gels [86]. Both peaks at -93 and - $97 \mathrm{ppm}$ are denoted as $\mathrm{Q}^{4}(3 \mathrm{Al})$ and assigned to the Al-rich N-A$\mathrm{S}$-H gels, which belong to the reactive and highly polymerised aluminate phases [62]. The $\mathrm{Q}^{4}(2 \mathrm{Al})$ and $\mathrm{Q}^{4}(1 \mathrm{Al})$ sites represent the more stable Si-rich N-A-S-H types gels, which are located at -103 and $-109 \mathrm{ppm}$, respectively [87]. Finally, The peak at $-116 \mathrm{ppm}$ is associated with the $\mathrm{Q}^{4}(0 \mathrm{Al})$ site that corresponds to the presence of crystalline phases including quartz, mullite and maghemite in the original fly ash $[9,62,88]$.

The ${ }^{29} \mathrm{Si}$ NMR spectra of AAFS pastes at different curing ages are illustrated in Fig. 5. As the curing age increases from $1 \mathrm{~d}$ to $28 \mathrm{~d}$, the broad peak located at $-84.23 \mathrm{ppm}$ is slightly shifted to a higher value $(-85.67 \mathrm{ppm})$, whereas the broad band centred at $-107.2 \mathrm{ppm}$ is slightly shifted to a lower value $(-105.9 \mathrm{ppm})$. This indicates the increase of polymerisation degree and cross-linking of gels over time. More specifically, the $\mathrm{Q}^{\mathrm{n}}(\mathrm{mAl})$ structural units of different phases are quantified and shown in Fig. 6 to further evaluate the nanostructure change. It can be found that there is a relatively high amount of $Q^{1}$ sites (18.15\%) within C-A-S-H gels at $1 \mathrm{~d}$. As the reaction continues, it is decreased significantly to $7.09 \%$ at $28 \mathrm{~d}$, while the content of $\mathrm{Q}^{2}(1 \mathrm{Al})$
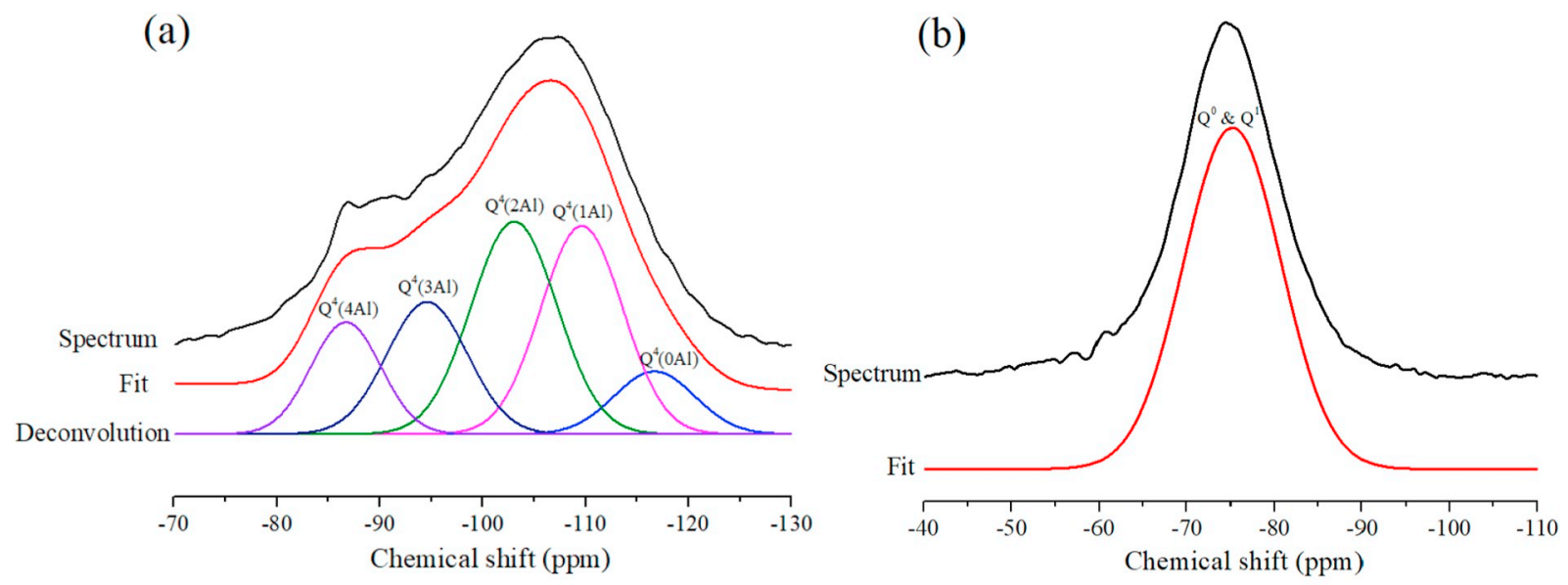

(c)

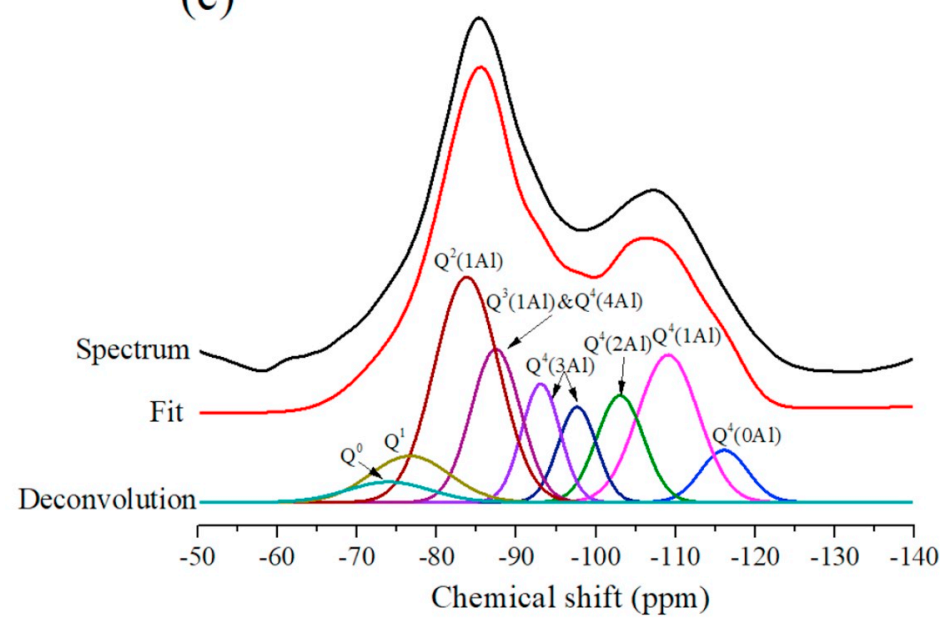

Fig. 4. ${ }^{29} \mathrm{Si}$ NMR spectra of (a) fly ash, (b) slag, and (c) AAFS paste ( $t=28 \mathrm{~d}$ ). 
Table 5

Deconvolution results of ${ }^{29} \mathrm{Si}$ MAS NMR spectra of AAFS pastes based on area percentage (\%).

\begin{tabular}{|c|c|c|c|c|c|c|c|c|c|c|c|c|}
\hline \multirow[t]{4}{*}{ Labels } & \multirow{4}{*}{$\begin{array}{l}\text { Unreacted slag } \\
Q^{0} \\
-74\end{array}$} & \multicolumn{7}{|c|}{ Reaction products } & \multirow{3}{*}{$\begin{array}{l}\text { Unreacted fly ash } \\
\mathrm{Q}^{4}(\mathrm{OAl})\end{array}$} & \multirow{4}{*}{$\begin{array}{l}\mathrm{Al} / \mathrm{Si} \text { ratio of } \\
\mathrm{C}-\mathrm{A}-\mathrm{S}-\mathrm{H}\end{array}$} & \multirow{4}{*}{$\begin{array}{l}\mathrm{Al} / \mathrm{Si} \text { ratio of N- } \\
\mathrm{C}-\mathrm{A}-\mathrm{S}-\mathrm{H}\end{array}$} & \multirow{4}{*}{$\begin{array}{l}\mathrm{Al} / \mathrm{Si} \text { ratio of } \\
\mathrm{N}-\mathrm{A}-\mathrm{S}-\mathrm{H}\end{array}$} \\
\hline & & \multicolumn{2}{|c|}{ C-A-S-H } & \multirow{2}{*}{$\begin{array}{l}\mathrm{N}-\mathrm{C}-\mathrm{A}-\mathrm{S}-\mathrm{H} \\
\mathrm{Q}^{3}(1 \mathrm{Al}) \& \\
\mathrm{Q}^{4}(4 \mathrm{Al})\end{array}$} & \multicolumn{2}{|c|}{ N-A-S-H (Al-rich) } & \multicolumn{2}{|c|}{ N-A-S-H (Si-rich) } & & & & \\
\hline & & $\mathrm{Q}^{1}$ & $\mathrm{Q}^{2}(1 \mathrm{Al})$ & & $\mathrm{Q}^{4}(3 \mathrm{~A}$ & & $\mathrm{Q}^{4}(2 \mathrm{Al})$ & $\mathrm{Q}^{4}(1 \mathrm{Al})$ & & & & \\
\hline & & -77 & -83 & -88 & -93 & -97 & -103 & -109 & -116 & & & \\
\hline $1-d$ & 3.45 & 18.15 & 25.41 & 11.14 & 6.69 & 5.21 & 9.09 & 14.87 & 5.99 & 0.29 & 0.20 & 0.53 \\
\hline $3-d$ & 3.12 & 15.69 & 27.24 & 10.40 & 8.36 & 4.68 & 9.20 & 17.90 & 3.41 & 0.32 & 0.20 & 0.54 \\
\hline $7-d$ & 3.38 & 10.24 & 27.79 & 13.75 & 10.03 & 3.76 & 8.88 & 16.96 & 5.21 & 0.36 & 0.27 & 0.56 \\
\hline 28-d & 3.22 & 7.04 & 27.87 & 14.57 & 8.73 & 7.03 & 9.66 & 17.17 & 4.71 & 0.40 & 0.29 & 0.57 \\
\hline
\end{tabular}

Note: Unreacted slag corresponds to the unaltered phases in the original slag; Unreacted fly ash corresponds to the unaltered phases in the original fly ash.

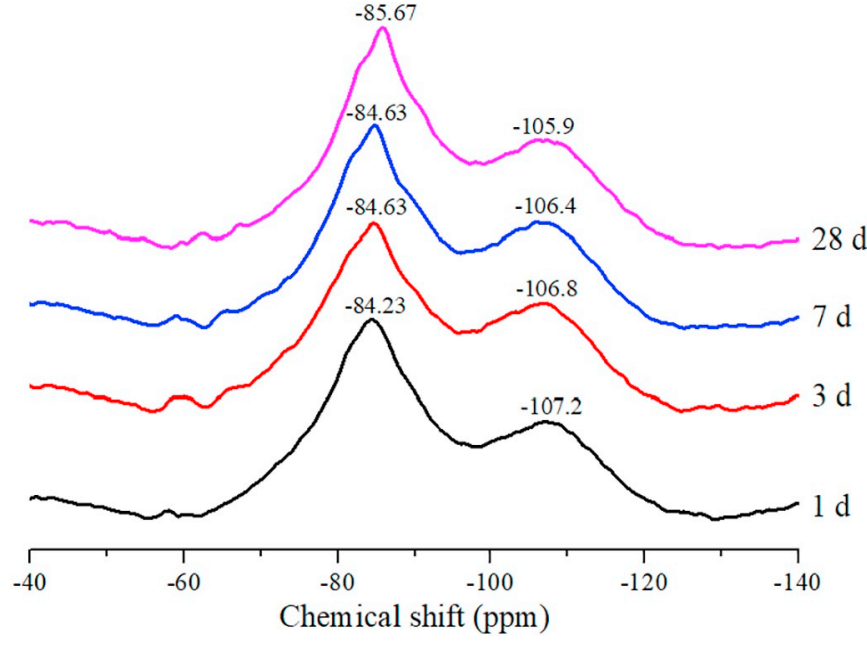

Fig. 5. ${ }^{29} \mathrm{Si}$ NMR spectra of AAFS pastes at different curing ages.

sites is increased steadily from $25.41 \%$ to $28.06 \%$. This is mainly because of the dissolution of more silicon and aluminium monomers from fly ash and slag, which would enhance the gel polymerisation and lead to the chain in C-A-S-H gels with more links. Additionally, with the increase of curing age from $1 \mathrm{~d}$ to $28 \mathrm{~d}$, an increase in the amount of $\mathrm{Q}^{3}(1 \mathrm{Al})$ and $\mathrm{Q}^{4}(4 \mathrm{Al})$ sites from $11.14 \%$ to $14.57 \%$ can also be observed, which indicates a higher degree of polymerisation and cross-linking within N-C-A-S-H gels at later curing ages. Moreover, the polymerisation degree of N-A-S-H gels is also improved with the increase of curing age. The amount of $\mathrm{Q}^{4}(3 \mathrm{Al})$ sites and $\mathrm{Q}^{4}(1 \mathrm{Al})$ sites increases from $11.90 \%(1 \mathrm{~d})$ to $15.76 \%(28 \mathrm{~d})$ and from $14.87 \%(1 \mathrm{~d})$ to $17.17 \%$ (28 d), respectively, while the $\mathrm{Q}^{4}(2 \mathrm{Al})$ sites remain stable at around $9 \%$ during curing process. The content of $\mathrm{Q}^{0}$ sites in unreacted slag is stable at around $3.2 \%$ at different curing ages, which is related to the presence of unaltered phases (i.e. crystalline phases) in the original slag. Nevertheless, the content of $\mathrm{Q}^{4}(0 \mathrm{Al})$ sites in unreacted fly ash is fluctuant between $3.41 \%$ and $5.99 \%$ at these curing ages, which can be attributed to the heterogeneity of the unaltered phases in the original fly ash. Finally, the Al/Si ratios of N-A-S-H gels, N-C-A-S-H gels and CA-S-H gels can be calculated using the following equations $[62,80]$ :

$\mathrm{Al} / \mathrm{Si}_{(\mathrm{N}-\mathrm{A}-\mathrm{S}-\mathrm{H})}=\frac{\sum_{\mathrm{n}=0}^{4} \frac{\mathrm{n}}{4} \mathrm{Q}^{4}(\mathrm{nAl})}{\sum_{\mathrm{n}=0}^{4} \mathrm{Q}^{4}(\mathrm{nAl})}$

$\mathrm{Al} / \mathrm{Si}_{(\mathrm{N}-\mathrm{C}-\mathrm{A}-\mathrm{S}-\mathrm{H})}=\frac{\mathrm{Q}^{3}(1 \mathrm{Al})}{\mathrm{Q}^{1}+\mathrm{Q}^{2}+\mathrm{Q}^{2}(1 \mathrm{Al})+\mathrm{Q}^{3}+\mathrm{Q}^{3}(1 \mathrm{Al})}$

$\mathrm{Al} / \mathrm{Si}_{(\mathrm{C}-\mathrm{A}-\mathrm{S}-\mathrm{H})}=\frac{\frac{1}{2} \mathrm{Q}^{2}(1 \mathrm{Al})}{\mathrm{Q}^{1}+\mathrm{Q}^{2}+\mathrm{Q}^{2}(1 \mathrm{Al})}$

$\mathrm{The} \mathrm{Al} / \mathrm{Si}$ ratios of different reaction products are presented in Table 5. It can be observed that the $\mathrm{Al} / \mathrm{Si}$ ratio of $\mathrm{N}-\mathrm{A}-\mathrm{S}-\mathrm{H}$ gels is higher than that of C-A-S-H gels and N-C-A-S-H gels, regardless of curing age. Nevertheless, as the curing age increases from $1 \mathrm{~d}$ to $28 \mathrm{~d}$, the $\mathrm{Al} / \mathrm{Si}$ ratios of C-A-S-H gels and N-C-A-S-H gels are increased steadily from

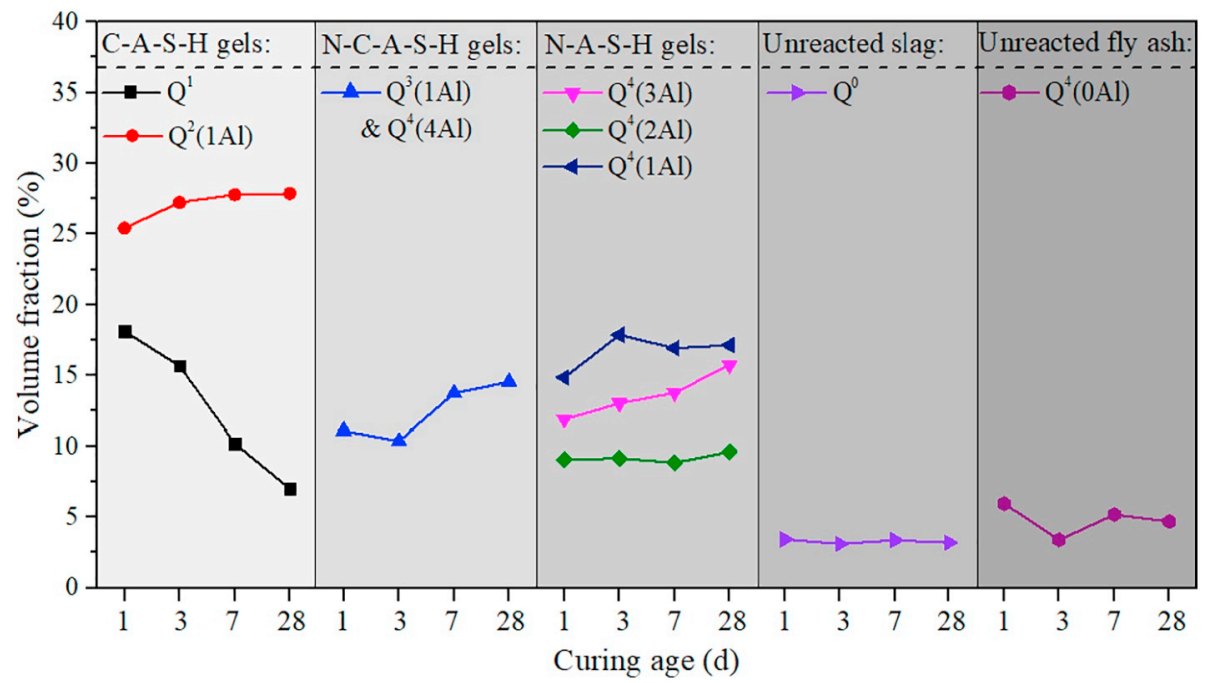

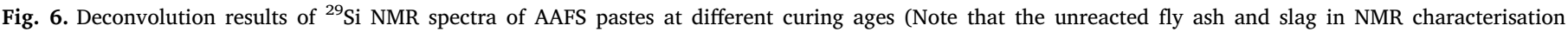
correspond to the unaltered phases in the original fly ash and slag, respectively). 
(a)

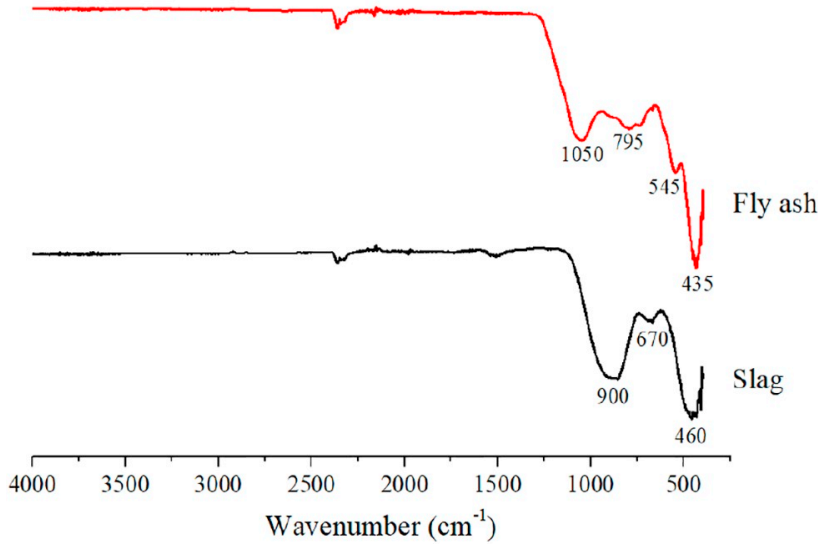

(b)

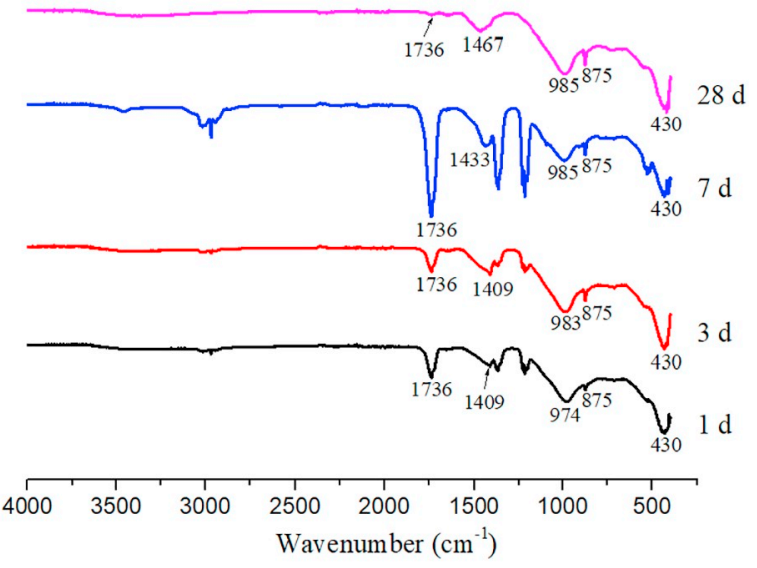

Fig. 7. FTIR spectra of (a) precursors and (b) AAFS pastes at different curing ages.

0.29 to 0.40 and from 0.20 to 0.29 , respectively, while the $\mathrm{Al} / \mathrm{Si}$ ratio of $\mathrm{N}-\mathrm{A}-\mathrm{S}-\mathrm{H}$ gels remains stable at around 0.5 . This suggests that the chemical composition of N-A-S-H gels is stable during the curing process, while that of C-A-S-H gels and N-C-A-S-H gels are changed along with the substitute of aluminate species.

\subsection{Chemical composition of gel matrix}

Fig. 7a shows the infrared spectra of fly ash and slag. The band between $1100 \mathrm{~cm}^{-1}$ and $900 \mathrm{~cm}^{-1}$ is related to the asymmetric stretching vibrations of Si-O-T bonds (T: tetrahedral Si or Al) [81]. The bands of fly ash and slag are centred at different positions $\left(1050 \mathrm{~cm}^{-1}\right.$ in fly ash and $900 \mathrm{~cm}^{-1}$ in slag), attributing to the chemical and structural differences between these two materials [9]. For fly ash, the band at $795 \mathrm{~cm}^{-1}$ correlates to the asymmetric stretch of quartz, while the shoulder at $545 \mathrm{~cm}^{-1}$ is associated with the $\mathrm{Al}-\mathrm{O}$ stretch of mullite [89]. The band at $435 \mathrm{~cm}^{-1}$ is related to the bending vibration of $\mathrm{SiO}_{4}$. Regarding the spectra of slag, the band at $670 \mathrm{~cm}^{-1}$ represents the Si-O$\mathrm{Si}$ bending vibration modes, while the band at $460 \mathrm{~cm}^{-1}$ is correlated to the $\mathrm{SiO}_{4}$ bending modes.

Fig. $7 \mathrm{~b}$ illustrates the infrared spectra of AAFS pastes at different curing ages. Alkali-activation produces a broad intense band at around $980 \mathrm{~cm}^{-1}$ in the spectra, attributing to the asymmetric stretching vibrations of Si-O-T bonds ( $\mathrm{T}$ : tetrahedral $\mathrm{Si}$ or $\mathrm{Al}$ ) in the chain structure of reaction products [81]. The position of the main band for these reaction products (i.e. $980 \mathrm{~cm}^{-1}$ ) is at a lower wavenumber than that for $\mathrm{N}$-A-S-H gels (i.e. $1020 \mathrm{~cm}^{-1}$ ) but at a higher wavenumber than that for C-A-S-H gels (i.e. $950 \mathrm{~cm}^{-1}$ ) [36], indicating the coexistence of different reaction products (e.g. N-A-S-H gels and C-A-S-H gels) [9]. With the increase of curing age from $1 \mathrm{~d}$ to $28 \mathrm{~d}$, the Si-O-T bonds within the reaction products shift towards higher wavenumber, from $974 \mathrm{~cm}^{-1}$ to $985 \mathrm{~cm}^{-1}$. This suggests that the increase of curing age promotes the polymerisation and cross-linking of the gels, potentially through the initial formation of C-A-S-H gels followed by the gradual development of N-A-S-H gels with a higher cross-linking degree [9]. It is noticed that the final position of this band $\left(985 \mathrm{~cm}^{-1}\right)$ in AAFS paste is at a lower wavenumber than that in AAF paste $\left(1020 \mathrm{~cm}^{-1}\right)$, implying that the presence of Ca leads to the formation of N-C-A-S-H gels [9].

A sharp band at $875 \mathrm{~cm}^{-1}$ in the spectra is associated with the asymmetric stretching of $\mathrm{AlO}_{4}{ }^{-}$group in Al-O-Si bonds within C-A-S-H gels [90], which becomes sharper with the increase of curing age. This indicates the increase of $\mathrm{Al}$ content within C-A-S-H gels, leading to a higher polymerisation and cross-linking degree of C-A-S-H gels. The intensive band between $1409 \mathrm{~cm}^{-1}$ and $1467 \mathrm{~cm}^{-1}$ is related to the asymmetric stretching model of O-C-O bonds of $\mathrm{CO}_{3}{ }^{2-}$ groups [90], suggesting that some superficial carbonation of samples would happen during the curing. The intensive band at $1736 \mathrm{~cm}^{-1}$ is associated with the stretching model of $\mathrm{C}=\mathrm{O}$ bonds of carboxylic acid group [91], corresponding to the modified polycarboxylate-based $\mathrm{SP}$ in the mixture. Lastly, the band at $430 \mathrm{~cm}^{-1}$ is related to the bending vibration of $\mathrm{SiO}_{4}$, indicating the presence of vitreous silica in the mixture [92]. The evolution of chemical composition of gel matrix is consistent with the nanostructure development of solid gel particles presented in NMR results (see Section 4.1).

\subsection{Microstructure of AAFS paste}

Fig. 8 shows the microstructure of AAFS paste. Based on the difference in morphology and grey value, different phases can be clearly identified in Fig. 8a, which can be roughly classified into two groups: (1) pore phase including cracks and pores, both of which are presented as black due to the low atomic number, and (2) solid phase including unreacted particles (i.e. fly ash and slag) and reaction products, which appear as light grey and dark grey, respectively. In order to subdivide different phases in AAFS paste, the greyscale histogram is subtracted from Fig. 8a and deconvolved into four Gaussian curves using a statistical analysis software called Peakfit (see Fig. 8b). The first Gaussian curve is assigned to pores, while the second Gaussian curve corresponds to reaction products. The third and fourth Gaussian curves are related to unreacted fly ash and slag, respectively. The point of interaction between Gauss 1 (Pores) and Gauss 2 (reaction products) is defined as the threshold value to determine the boundary between pores and reaction products. Similarly, the threshold value of frontier between reaction products and unreacted fly ash is set as the interaction point between Gauss 2 (reaction products) and Gauss 3 (unreacted fly ash). Unreacted fly ash and slag are separated based on the interaction point between Gauss 3 (unreacted fly ash) and Gauss 4 (unreacted slag). Here, the threshold values of 43, 155 and 184 are obtained to segment pores, reaction products, unreacted fly ash and unreacted slag (see Fig. 8b). Accordingly, as shown in Fig. 8c, different phases including unreacted slag, unreacted fly ash, reaction products and pores are distinguished and labelled in different colours. The unreacted slag is labelled in red, while the unreacted fly ash is presented as yellow (see Fig. 8d). It is interesting to note that the reaction products cover a wide range of colours from light blue to light green, which indicates that different types of reaction products form together within the AAFS paste (see Fig. 8e). The pores are labelled in blue (see Fig. 8f).

Fig. 9 shows the BSEM images of AAFS pastes at different curing ages. The microstructure of solid AAFS pastes is significantly changed with the increase of curing age. Initially, the morphology of most precursors (fly ash and slag) at $1 \mathrm{~d}$ is not altered by the alkaline activator, except for the morphology change in some small particles (see Fig. 9a). 
(a) Origin BSEM image

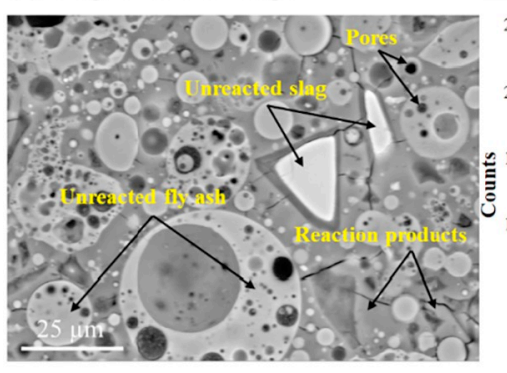

(d) Unreacted fly ash and slag

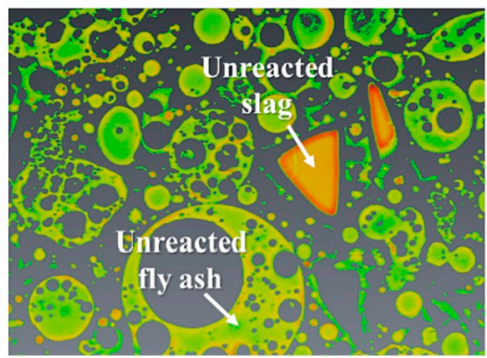

(b) Greyscale histogram

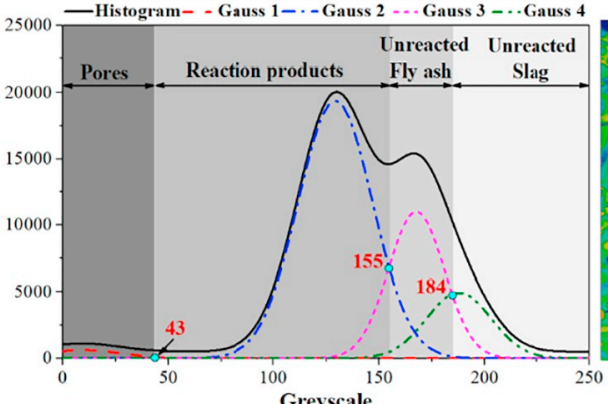

(e) Reaction products

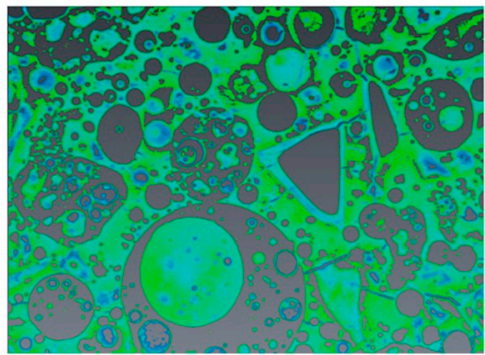

(c) Polychromatic BSEM image

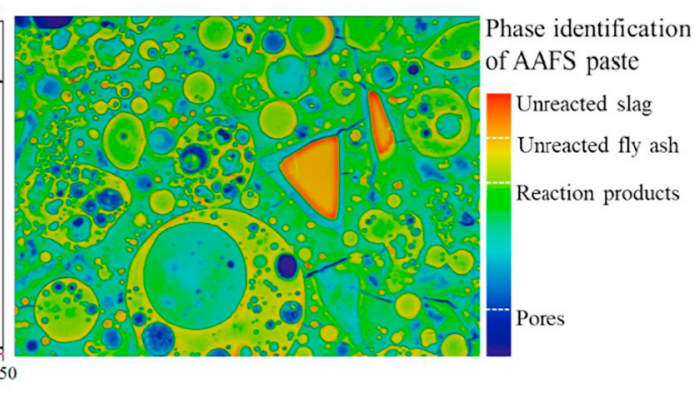

(f) Pores

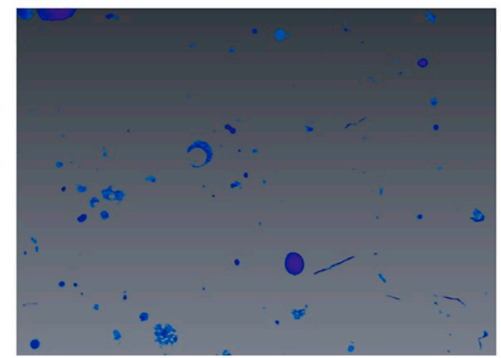

Fig. 8. Typical polychromatic greyscale image of AAFS paste $(t=28 \mathrm{~d})$.

This is mainly because the finer particles are easier to be activated at early curing ages [93,94]. Additionally, the reaction products are presented as dark grey, which implies that the density of their structures is relatively low. This is because of the low reaction degree at early curing ages. As the curing age increases to $3 \mathrm{~d}$, the change in morphology of fly ash and slag becomes obvious, even for the relatively large particles (see Fig. 9b). At this stage, the change in morphology of slag is more significant than that of fly ash due to its higher reactivity. Normally, slag has over $90 \%$ vitreous phase which contributes to alkaline activation, while fly ash only has about $50 \%$ vitreous phase and the remaining constituents (crystalline phase) in fly ash are difficult to be activated and thus need longer time for reaction [93]. As the reaction proceeds with time from $7 \mathrm{~d}$ to $28 \mathrm{~d}$, the change in morphology of slag becomes more obvious, along with a significant reduction in the size of original slag particles, and some fully reacted slag can be found. During the activation of fly ash, its morphology is also changed significantly, (a) $1 \mathrm{~d}$

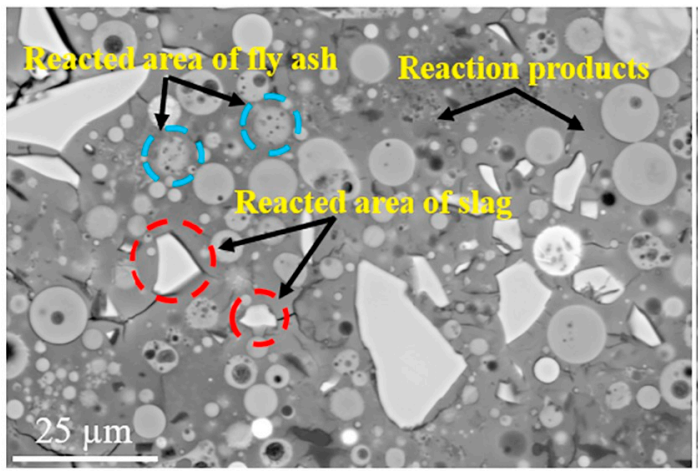

(a) $7 \mathrm{~d}$

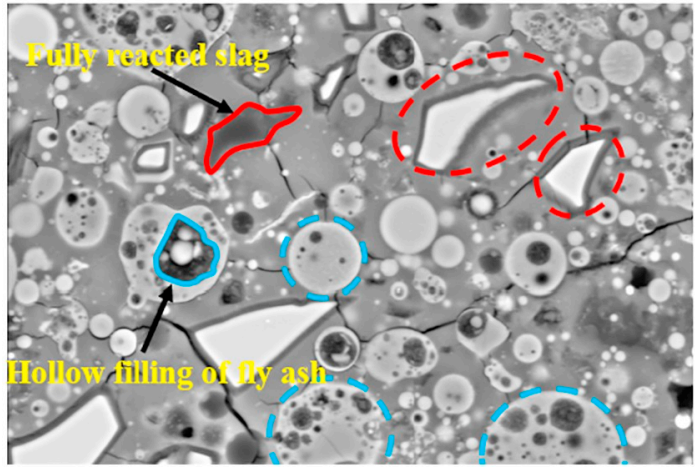

(b) $3 \mathrm{~d}$

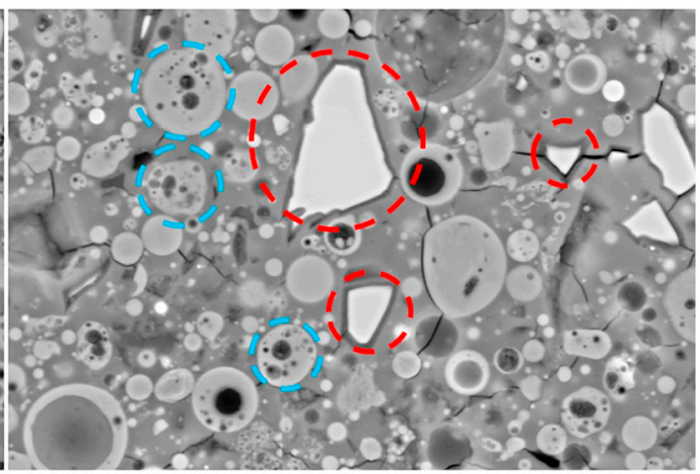

(b) $28 \mathrm{~d}$

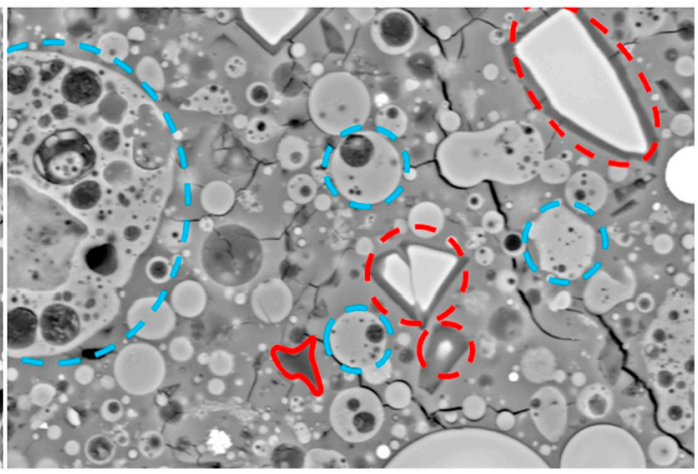

Fig. 9. BSEM images of AAFS pastes at different curing ages. 
with the filling of reaction products into the original hallow within fly ash. Furthermore, the reaction products at later curing ages are presented as a lighter grey than that at early curing ages ( $1 \mathrm{~d}$ and $3 \mathrm{~d}$ ), suggesting that the microstructure becomes compact at later curing ages.

To further understand the evolution of microstructure, the reaction degrees of fly ash and slag were calculated based on a series of analysis on 10 BSEM images (magnification: $250 \times$ ) of each sample. Combined with the image analysis mentioned in Fig. 8, unreacted fly ash and slag were distinguished from each image, and their volume fractions were characterised using an open-source image analysis software called Fiji [95]. Subsequently, the reaction degrees of fly ash and slag can be calculated as follows:

$\alpha_{\text {fly }- \text { ash }}=\left(1-\frac{\mathrm{V}_{(\mathrm{t}) \mathrm{fly} \text { ash }}}{\mathrm{V}_{(0) \mathrm{fly} \text { ash }}}\right) \times 100 \%$

$\alpha_{\text {slag }}=\left(1-\frac{V_{(t) \text { slag }}}{V_{(0) \text { slag }}}\right) \times 100 \%$

where $\alpha_{f l y-a s h}$ is the reaction degree of fly ash, $V_{(t) f l y-a s h}$ is the volume fraction of unreacted fly ash at age $t$ obtained from the BSEM image analysis, $V_{(0) f l y ~ a s h ~}$ is the initial volume fraction of fly ash (before reaction) calculated based on the mixture quantity in Table 3 (i.e. $43.28 \%), \alpha_{\text {slag }}$ is the reaction degree of slag, $V_{(t) \text { slag }}$ is the volume fraction of unreacted slag at age $t$ obtained from the BSEM image analysis, and $V_{(0) s l a g}$ is the initial volume fraction of slag (before reaction) (i.e. $11.19 \%)$.

Fig. 10 shows the reaction degree of fly ash and slag at different curing ages. It can be found that the reaction degree of slag is higher than that of fly ash, especially at early $7 \mathrm{~d}$. Within the first $7 \mathrm{~d}$, the reaction degree of slag (46.66\%-58.96\%) is obviously higher than that of fly ash $(30.48 \%-44.83 \%)$, which can be attributed to the high content of vitreous phase within slag. The high reaction degree of slag is related to the high dissolution of calcium silicates from slag, which would promote the formation of C-A-S-H gels and N-C-A-S-H gels in AAFS paste. In comparison, there is less dissolution of aluminate silicates from fly ash due to its relatively low reaction degree. Between $7 \mathrm{~d}$ and $28 \mathrm{~d}$, the difference of reaction degree between slag and fly ash becomes less, where the reaction degree of slag (74.36\%) is $10 \%$ higher than that of fly ash (64.52\%). This indicates that the dissolution rate of calcium silicates from slag becomes slow, while the dissolution rate of aluminate silicates from fly ash increases, which would promote the formation of N-A-S-H gels.

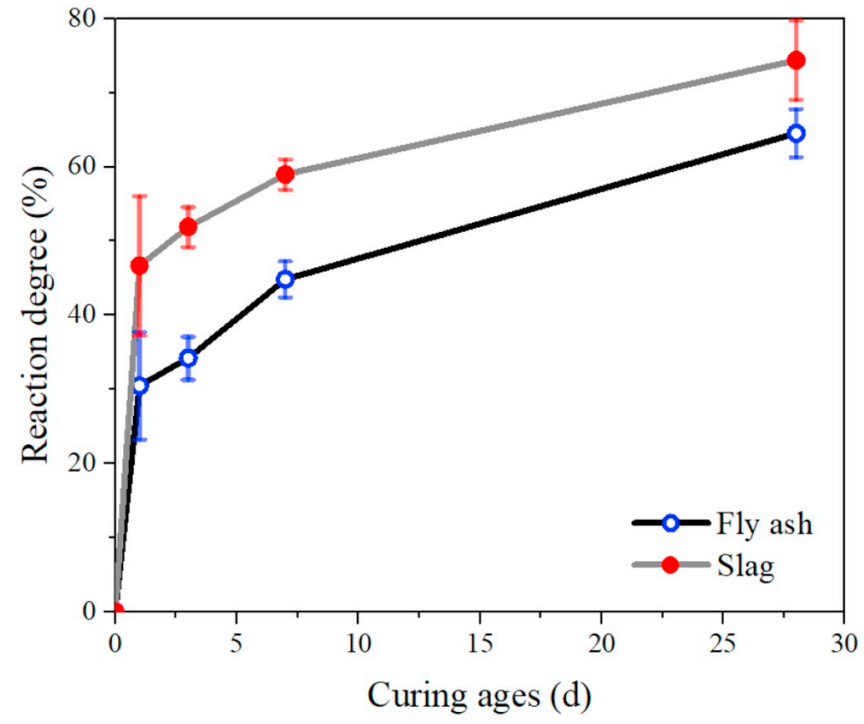

Fig. 10. Reaction degree of fly ash and slag at different curing ages.
Fig. 11 shows the pore size distribution of AAFS pastes at different curing ages obtained from MIP tests. The pore size decreases dramatically in the early $7 \mathrm{~d}$ and then decreases slightly with increasing curing age from $7 \mathrm{~d}$ to $28 \mathrm{~d}$ (see Fig. 11a). The pores with size between 5 and $30 \mathrm{~nm}$ exhibit obvious changes compared to other pores. Generally, the pores with size between 2.5 and $10 \mathrm{~nm}$ belong to small gel pores, while the pores with size in the range of 10 and $50 \mathrm{~nm}$ can be assigned to medium capillary pores [96]. Hence, it is suggested that both gel pores and capillary pores in AAFS pastes would be changed and refined due to the newly formed reaction products. Additionally, the total porosity of AAFS pastes is decreased significantly from about $28 \%$ to $10 \%$ with the increase of curing age from $1 \mathrm{~d}$ to $28 \mathrm{~d}$, leading to a compact microstructure of AAFS pastes at later curing ages (see Fig. 11b).

\subsection{Mechanical properties of individual phases}

\subsubsection{Qualitative analysis}

The characterisation of mechanical properties of different phases, i.e., unreacted fly ash, unreacted slag and reaction products, was performed based on the nanoindentation test, where the classical nanoindentation test and grid nanoindentation test have been made. The classical nanoindentation test helps to characterise the load-displacement behaviour of different phases and understand the difference in their mechanical properties. In this study, the classical nanoindentation test of each phase was performed on 10 different locations to ensure the results can possibly represent the load-displacement behaviour of each phase. Fig. 12 shows the load-displacement curves of unreacted fly ash, unreacted slag and reaction products. A significant difference in the displacement and the slope of unloading portion between these phases can be well recognised due to the dissimilarity in elastic modulus and hardness among the corresponding material phases. The displacement of unreacted fly ash is generally lower than that of unreacted slag and reaction products, but the slopes of the curves for unreacted fly ash are higher than that of unreacted slag and reaction products. This suggests that the unreacted fly ash has the highest elastic modulus and hardness, followed by unreacted slag and reaction products. In addition, it can be observed that the same phase exhibits different load-displacement behaviour. Regarding unreacted particles, the displacement of unreacted fly ash and slag is changed in the range of 176-385 nm and 176-449 nm, respectively, which is related to the heterogeneity of fly ash and slag. In the terms of reaction products, the displacement is changed from $416 \mathrm{~nm}$ to $706 \mathrm{~nm}$, corresponding to the formation of different reaction products.

Regarding the grid nanoindentation test, it can be used to reflect the mechanical properties and provide the dataset for statistical analysis. The obtained discrete data can be converted into a mapping of micromechanical properties by linearly interpolating the nodal values over the $100 \mu \mathrm{m} \times 100 \mu \mathrm{m}$ grid region with spacing of $10 \mu \mathrm{m}$ [53]. As shown in Fig. 13, the elastic modulus and hardness were calculated and plotted in two-dimensional contour maps according to the load-displacement curves. It can be observed that there exists a good correlation between elastic modulus and hardness. Thus, the discussion will be mainly focused on the elastic modulus in the following sections. Within the contour maps of elastic modulus, the red area represents the hard matrix with a relatively high elastic modulus, while the blue area stands for the soft matrix with a relatively low elastic modulus. Combined with the analysis of microstructure (see Fig. 9) and load-displacement curves above (see Fig. 12), the contour maps of elastic modulus can be roughly separated into three categories, i.e., unreacted particles, reaction products, and pores. Herein, the unreacted particles (fly ash and slag) cover the colours from green to red due to their relatively high elastic modulus, while the pores with the lowest elastic modulus $(<0.1 \mathrm{GPa})$ are represented as deep blue. The area with middle elastic modulus is assigned to reaction products, which cover the colours from blue to light green. Similar to the microstructure characterisation in Fig. 8, the reaction products also cover a wide range of colours in the mechanical 
(a)

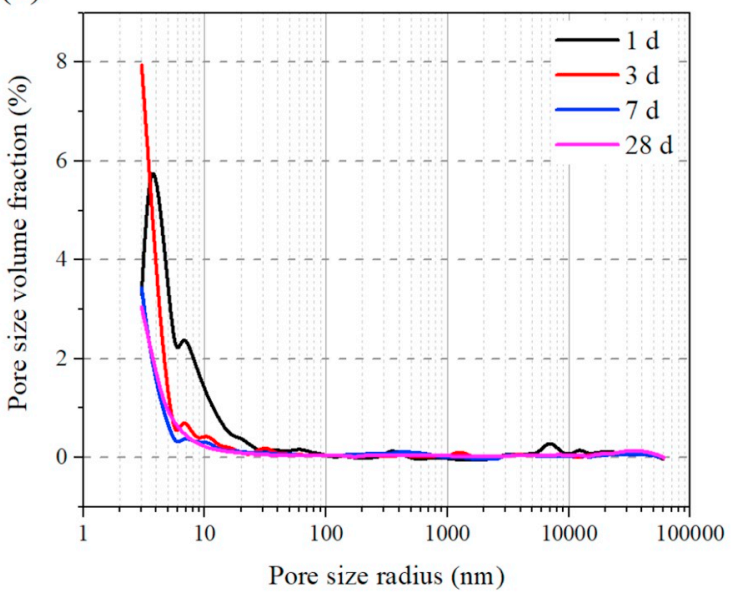

(b)

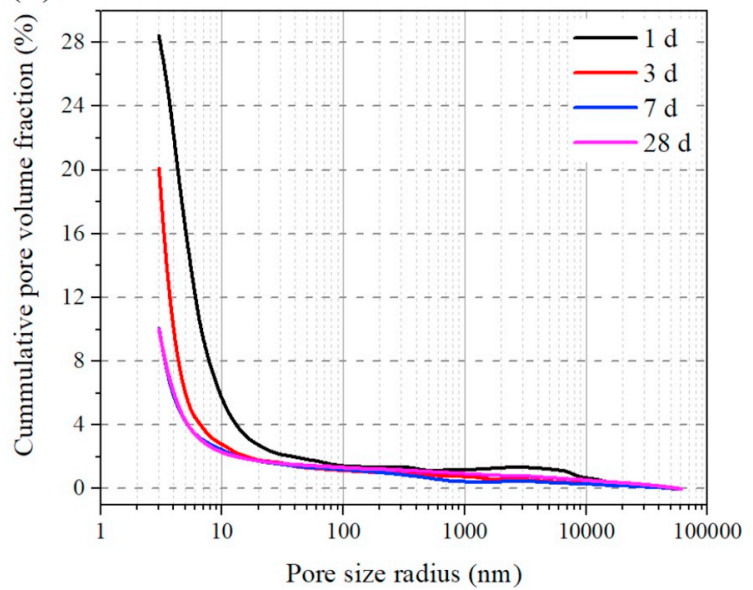

Fig. 11. Pore size distribution of AAFS pastes at different curing ages.

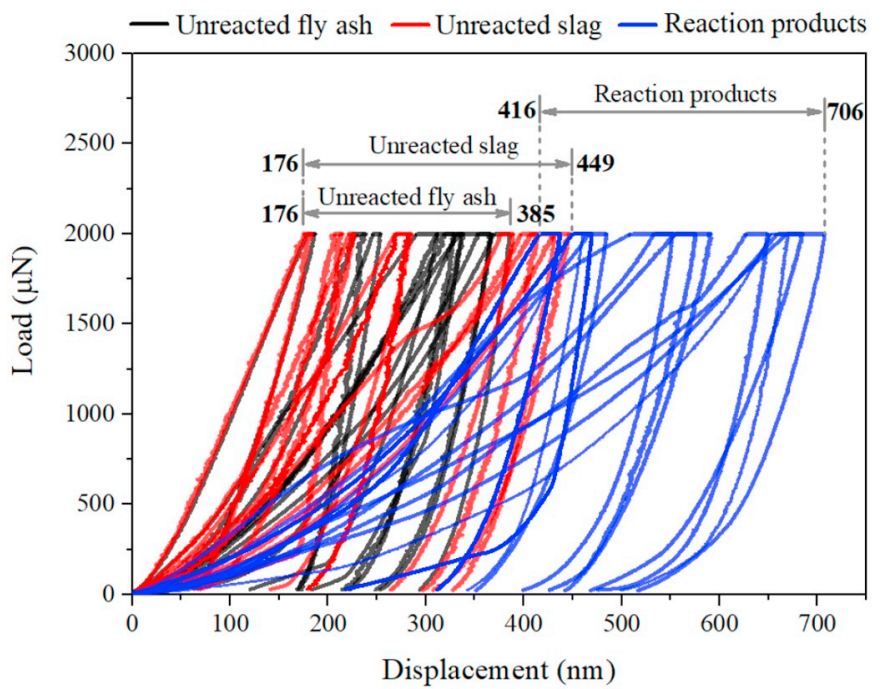

Fig. 12. Load-displacement curves of different phases in AAFS paste $(t=1 \mathrm{~d})$.

property map. It also suggests the existence of complex reaction products, including N-A-S-H gels, N-C-A-S-H gels and C-A-S-H gels. It can be seen from the contour map in Fig. 13 that the area with unreacted particles is obvious in the map of elastic modulus at early curing ages $(<3 \mathrm{~d})$, while most part of contour map are occupied by the reaction products at later curing ages ( $>7 \mathrm{~d}$ ).

\subsubsection{Quantitative analysis}

To further investigate the micromechanical properties of AAFS paste, a statistical Gaussian deconvolution method was subsequently used to determine the elastic moduli of different phases in AAFS paste. Gaussian deconvolution method is commonly adopted to identify clusters of data with distinct micromechanical properties based on the obtained experimental data [34]. As shown in Fig. 14, the determination of elastic moduli of different phases includes four steps: (i) experimental fitting, (ii) Gaussian deconvolution, (iii) phases identification, and (iv) data analysis. Firstly, as seen in Fig. 14a, the frequency density (normalised histogram with a bin size of $5 \mathrm{GPa}$ ) of the experimental data in terms of elastic modulus is fit by the probability density function (PDF) using a statistical analysis software called OriginPro. Since the PDF can be assumed as Gaussian distribution [27,97], the experimental PDF is then deconvolved by the Gaussian distribution curves to generate the theoretical PDF for experimental data (see Fig. 14b). The number of Gaussian distribution curves is determined based on the microstructural and chemical analysis mentioned in Sections 4.1-4.3. Here, six phases including pores, three types of reaction products, and two types of unreacted particles were identified. Nevertheless, the elastic modulus of pore phase $(<0.1 \mathrm{GPa})$ was not considered in the deconvolution process because its frequency density of the measured quantity is too small to quantify. Thus, five phases including unreacted fly ash, unreacted slag, N-A-S-H gels, N-C-A-S-H gels, and C-A-S-H gels were considered in the Gaussian deconvolution. Accordingly, the dataset of elastic modulus can be segmented into five different mechanically distinct phases (see Fig. 14b). Afterwards, as shown in Fig. 14c, these five different phases can be further identified based on the literature of typical elastic modulus ranges for alkali-activated materials $[23,33,98]$, where the typical order of elastic modulus for different phases is N-A-S-H $<$ N-C-A-S-H $<$ C-A-S-H $<$ slag $<$ fly ash. Finally, the mean values of elastic modulus and volume fraction of each phase can be characterised based on the Gaussian distribution curves (see Fig. 14d).

As shown in Fig. 15, the Gaussian deconvolution was successfully undertaken to identify the clusters of data with distinct elastic modulus and separate different phases in the gel matrix. Taking the AAFS sample cured for $1 \mathrm{~d}$ as an example (Fig. 15a), the first peak with the largest and most frequent region is corresponding to N-A-S-H gels with elastic modulus of around $10 \mathrm{GPa}$. The second peak is assigned to the hybrid type gels called N-C-A-S-H with elastic modulus of around $20 \mathrm{GPa}$. The third peak with the highest elastic modulus of around $30 \mathrm{GPa}$ among reaction products is associated with the C-A-S-H gels due to their very densely packed structure [12]. The fourth peak of around $50 \mathrm{GPa}$ is related to the unreacted slag, while the fifth peak of around $75 \mathrm{GPa}$ is associated with the unreacted fly ash. These findings are in good agreement with the nanoindentation load-displacement curves presented in Fig. 12, where the unreacted fly ash has the highest stiffness, followed by unreacted slag and reaction products. The distinction of micromechanical properties between these five phases is also clearly presented in the cluster allocation of elastic modulus and hardness (see Fig. 15a). Based on the Gaussian deconvolution above, the mean elastic modulus and the volume fraction of individual solid phases are summarised in Table 6. In addition, a statistical analysis is performed using one-way analysis of variance (ANOVA) method to determine whether there is any significant difference in elastic modulus between different phases. In this method, the probability value (i.e. $P$-value) is compared with the significance level to determine whether the observed groups have significant differences [99]. The significance level is commonly set as 0.05 [100]. If the $P$-value is lower than 0.05 , there is a significant difference between the observed groups. Otherwise, the observed groups have no significant difference (i.e. $P$-value $>$.05). Moreover, if 

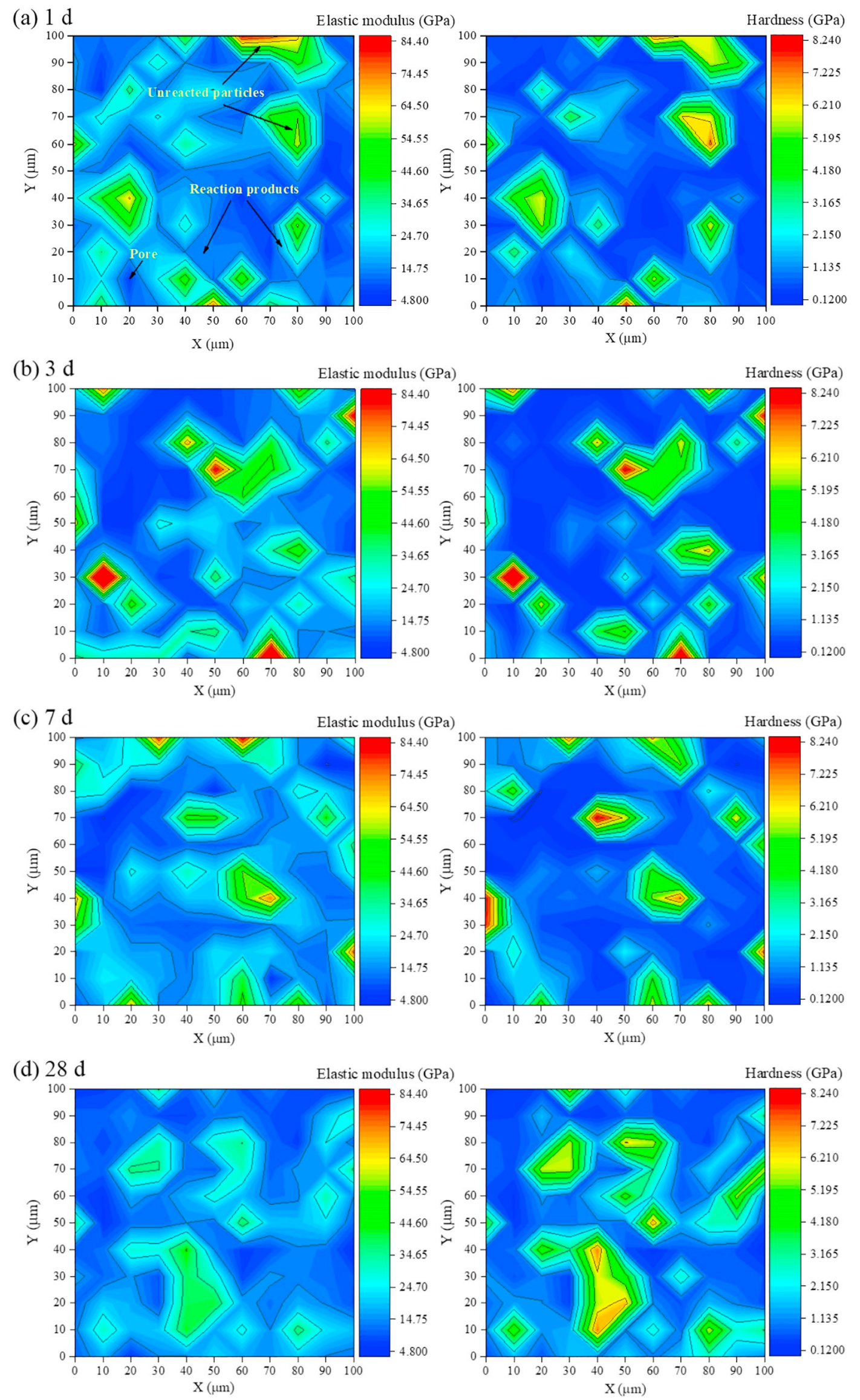

Fig. 13. Contour map of elastic modulus and hardness of AAFS pastes at different curing ages. 
(a)

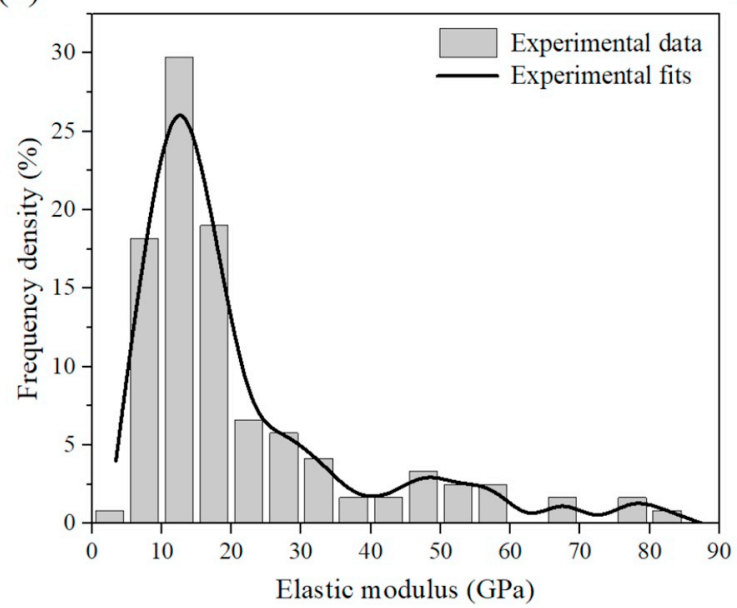

(c)

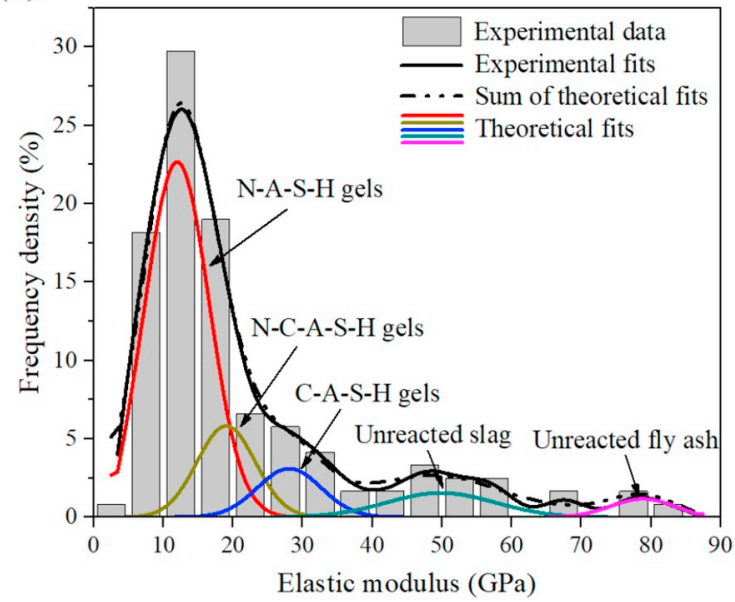

(b)

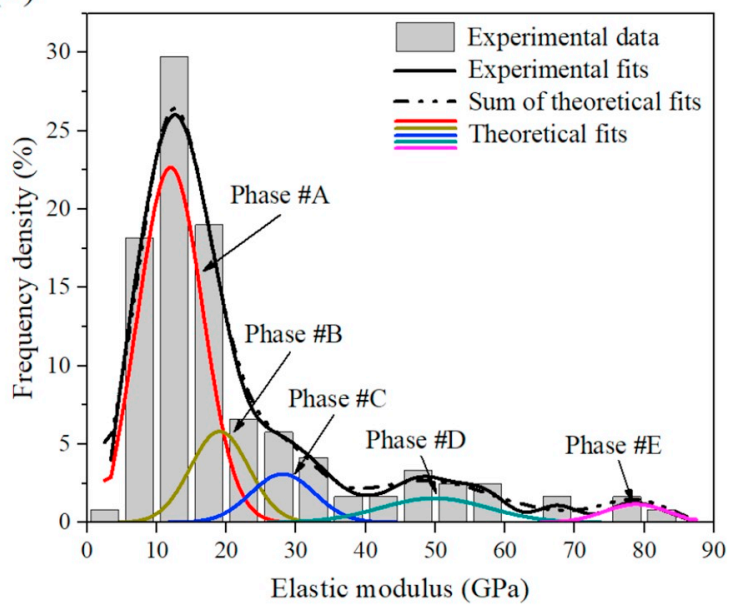

(d)

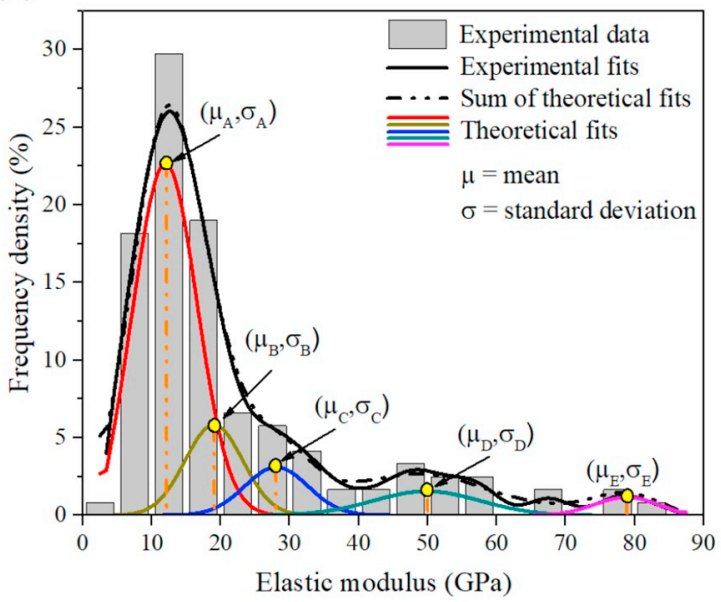

Fig. 14. Schematic diagram for the determination of elastic modulus of different phases in AAFS paste $(t=1 \mathrm{~d})$.

the $P$-value is lower than 0.01 , it means that the observed groups have a strong significant difference with each other. The results of ANOVA tests are presented in Tables 7 and 8.

Fig. 16 shows the elastic moduli of different phases in AAFS paste at different curing ages. There exists an obvious distinction of elastic modulus between different phases, regardless of curing ages. The statistical analysis also indicates a strong significant difference $(P$ value $<.01$ ) of elastic modulus between different phases (see Tables 7 and 8). The order of elastic modulus among these five phases is N-A-S-H gels $<$ N-C-A-S-H gels < C-A-S-H gels < unreacted slag $<$ unreacted fly ash. The elastic modulus of N-A-S-H gels is stable at 11-12 GPa during the curing process. Regarding the N-C-A-S-H gels, the elastic modulus is relatively low, which is about $19 \mathrm{GPa}$ at $1 \mathrm{~d}$ and then increases slightly to $23 \mathrm{GPa}$ at $28 \mathrm{~d}$. Consequently, the difference of elastic modulus between N-A-S-H gels and N-C-A-S-H gels becomes more obvious at later curing ages. This phenomenon can also be recognised in the cluster allocation of elastic modulus and hardness in Fig. 15. The cluster of N-A-S-H gels is almost overlapped with that of N-C-A-S-H gels at $1 \mathrm{~d}$ (see Fig. 15a). However, the overlap area between these two gels becomes smaller and the boundary between them tends to be clear at later curing ages (see Fig. 15b to d). Regarding the elastic modulus of C-A-S$\mathrm{H}$ gels, it is obviously higher than that of N-A-S-H gels and N-C-A-S-H gels, regardless of curing age. In addition, the elastic modulus of C-A-S$\mathrm{H}$ gels is increased steadily from $28 \mathrm{GPa}$ to $35 \mathrm{GPa}$ with increasing curing age from $1 \mathrm{~d}$ to $28 \mathrm{~d}$. Regarding the unreacted particles, the elastic modulus of unreacted slag is decreased from $50 \mathrm{GPa}$ to $48 \mathrm{GPa}$, while that of unreacted fly ash is decreased from $78 \mathrm{GPa}$ to $71 \mathrm{GPa}$. As the unreacted slag and fly ash cannot be found in the testing area at $28 \mathrm{~d}$, only the 7-d data are plotted here.

Fig. 17 presents the change in volume fraction of different phases in terms of elastic modulus against curing age. This information would help further understand the evolution of elastic moduli of different phases and their contribution to the overall elastic modulus of AAFS. It can be found that the volume fraction of N-A-S-H gels is obviously higher than that of N-C-A-S-H gels and C-A-S-H gels, regardless of curing age. Besides, it can be observed that the volume fraction of each phase is changed with the increase of curing age. For N-A-S-H gels, the content decreases steadily from $65.01 \%$ to $54.76 \%$ at early $7 \mathrm{~d}$, but increases significantly at later curing ages, reaching $77.98 \%$ at $28 \mathrm{~d}$. In contrast, the amount of N-C-A-S-H gels increases steadily from $15.24 \%$ to $37.72 \%$ with the increase of curing age from $1 \mathrm{~d}$ to $7 \mathrm{~d}$ and then decreases dramatically to $9.43 \%$ at $28 \mathrm{~d}$. The volume fraction of C-A-S$\mathrm{H}$ gels is fluctuant at around $9 \%$. The nonlinear development of micromechanical properties of different reaction products implies that the interaction between fly ash and slag exists during the reaction process. This phenomenon has also been found in other studies on chemical characterisation of AAFS [13]. The content of unreacted slag and fly ash decreases steadily with the increase of curing age.

\subsection{Effective mechanical properties of AAFS paste}

Continuum micromechanics provides a link between the mechanical properties of individual phases at micro-scale and AAFS paste at macroscale. Here, the effective mechanical properties of AAFS paste including 
(a) $1 \mathrm{~d}$
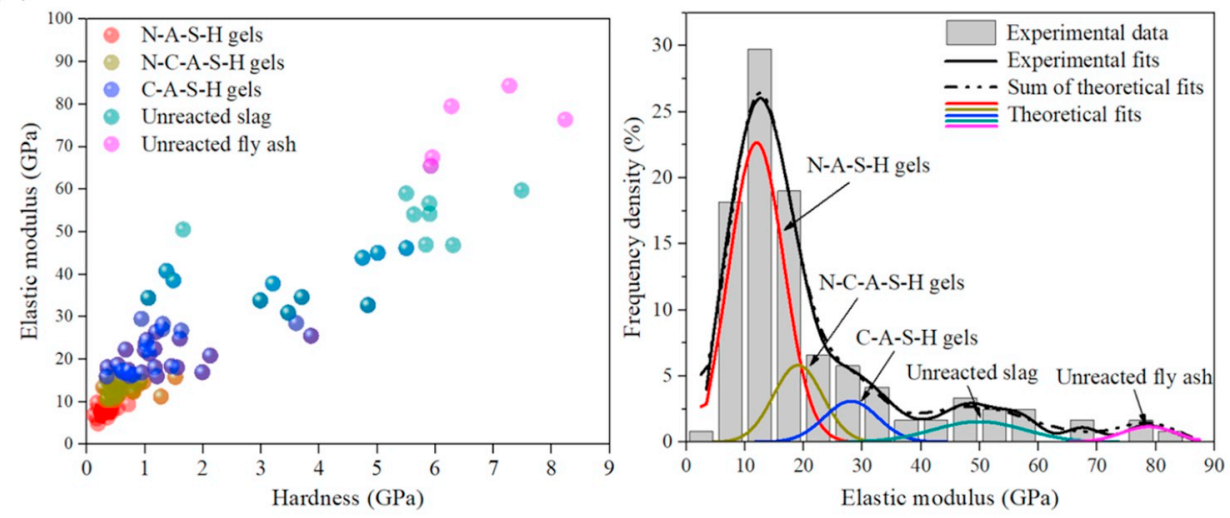

(b) $3 \mathrm{~d}$
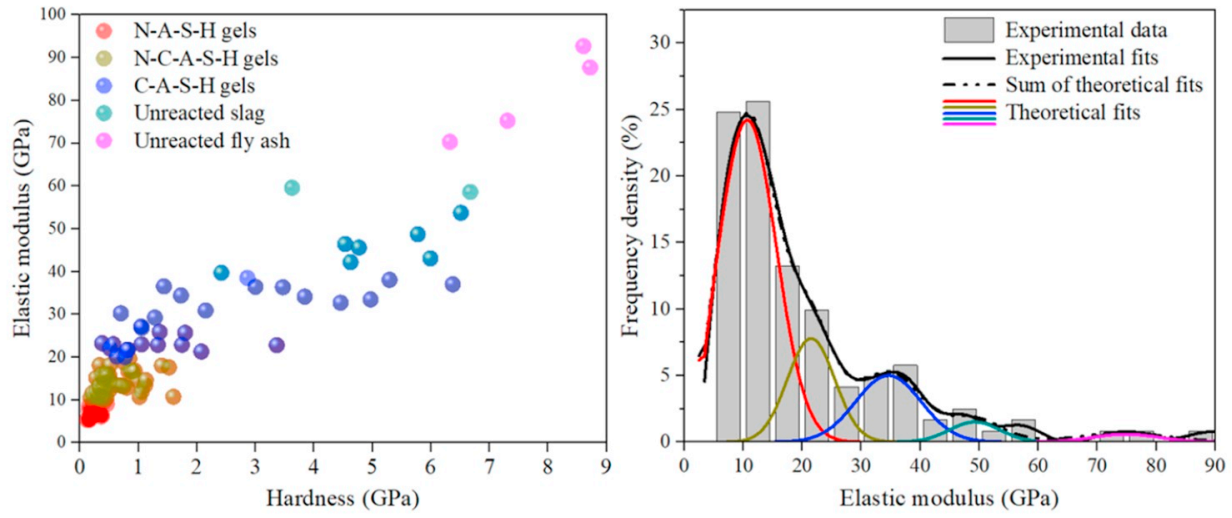

(c) $7 \mathrm{~d}$
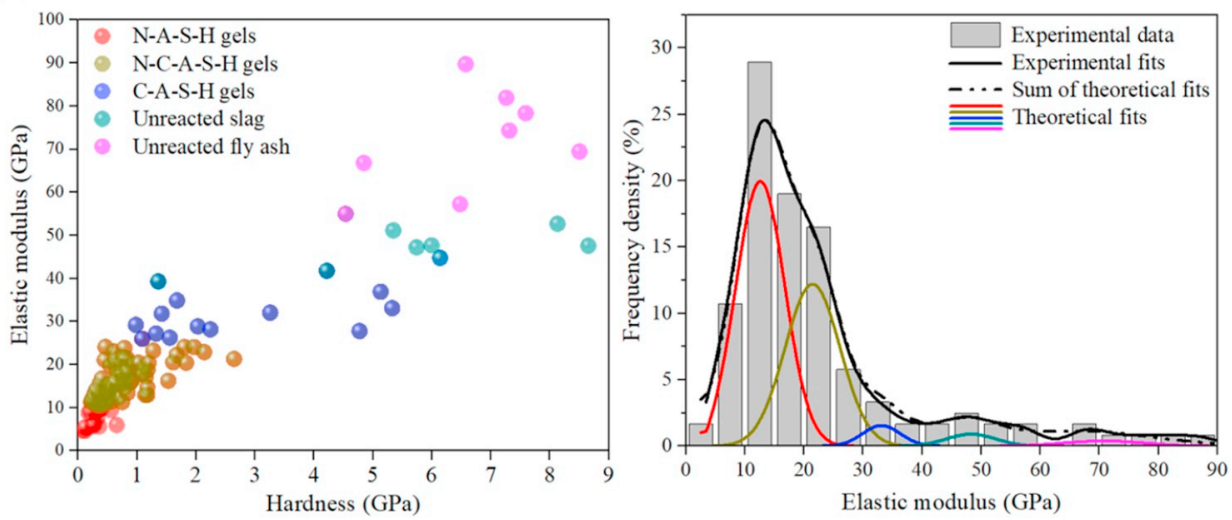

(d) $28 \mathrm{~d}$
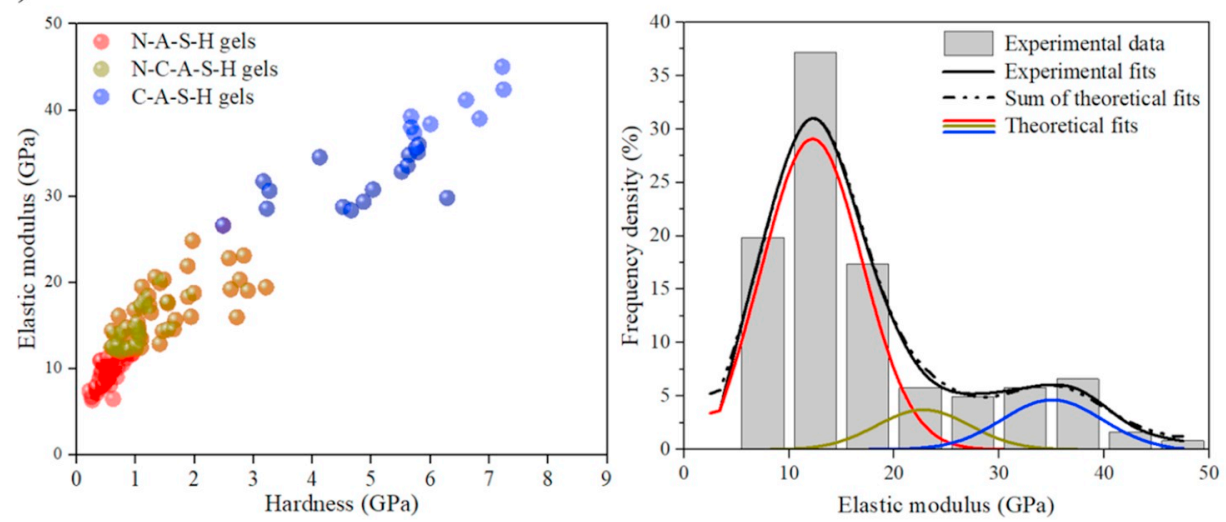


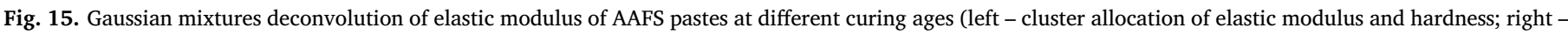
deconvolved elastic modulus corresponding to different phases).

effective bulk modulus $\left(K_{\text {eff }}\right)$ and effective shear modulus $\left(G_{\text {eff }}\right)$ were calculated using the self-consistent continuum micromechanics model given as follows [50]:

$\mathrm{K}_{\text {eff }}=\frac{\sum_{\mathrm{i}=1}^{\mathrm{n}} \mathrm{f}_{\mathrm{i}} \mathrm{K}_{\mathrm{i}}\left[1+\alpha\left(\frac{\mathrm{K}_{\mathrm{i}}}{\mathrm{K}_{0}}-1\right)\right]^{-1}}{\sum_{\mathrm{i}=1}^{\mathrm{n}} \mathrm{f}_{\mathrm{i}}\left[1+\alpha\left(\frac{\mathrm{K}_{\mathrm{i}}}{\mathrm{K}_{0}}-1\right)\right]^{-1}}$

$\mathrm{G}_{\text {eff }}=\frac{\sum_{\mathrm{i}=1}^{\mathrm{n}} \mathrm{f}_{\mathrm{i}} \mathrm{G}_{\mathrm{i}}\left[1+\beta\left(\frac{\mathrm{G}_{\mathrm{i}}}{\mathrm{G}_{0}}-1\right)\right]^{-1}}{\sum_{\mathrm{i}=1}^{\mathrm{n}} \mathrm{f}_{\mathrm{i}}\left[1+\beta\left(\frac{\mathrm{G}_{\mathrm{i}}}{\mathrm{G}_{0}}-1\right)\right]^{-1}}$

$\alpha=\frac{3 \mathrm{~K}_{0}}{3 \mathrm{~K}_{0}+4 \mathrm{G}_{0}}$

$\beta=\frac{6 \mathrm{~K}_{0}+12 \mathrm{G}_{0}}{15 \mathrm{~K}_{0}+20 \mathrm{G}_{0}}$

where $f_{i}$ is the volume fraction of the $i^{\text {th }}$ phase, $K_{i}$ is its bulk modulus, and $G_{i}$ is its shear modulus. A reference medium is regarded as the 0th phase, which is equal to the homogenised medium itself in the selfconsistent model, leading to $K_{O}=K_{\text {eff }}$ and $G_{O}=G_{\text {eff }}$ after several iterations.

In addition, the effective elastic modulus ( $E_{\text {eff }}$ ) for AAFS paste can be calculated based on its $K_{\text {eff }}$ and $G_{\text {eff }}$ as:

$\mathrm{E}_{\text {eff }}=\frac{9 \mathrm{~K}_{\text {eff }} \mathrm{G}_{\text {eff }}}{3 \mathrm{~K}_{\mathrm{eff}}+\mathrm{G}_{\mathrm{eff}}}$

Here, five different phases were identified and conducted to homogenise the effective modulus of AAFS paste. Based on the obtained $K$ and $G$ of individual phases (see Table 9 ), $K_{\text {eff }}$ and $G_{\text {eff }}$ of AAFS pastes at various curing ages were calculated and presented in Table 10. $E_{\text {eff }}$ was also calculated based on $K_{\text {eff }}$ and $G_{\text {eff }}$ (see Table 10). It can be observed that $E_{\text {eff }}$ and $K_{\text {eff }}$ are fluctuant in the range of 14.69-16.80 GPa and 8.16-9.33 GPa, respectively, while $G_{\text {eff }}$ is stable between $6.12 \mathrm{GPa}$ and $7 \mathrm{GPa}$.

\section{Discussion}

The heterogeneous microstructures of AAFS paste can be divided into different levels with multiscale (Level 0 to Level II) and multiphase (pores, reaction products and unreacted particles), which are strongly associated with the micro-scale and macro-scale mechanical properties. The characterisation of micromechanical properties enables us to build the links between microstructure and mechanical properties and provides a better understanding of the influences of different phases on the overall performance of paste matrix [22,48]. In the following subsections, the microstructure-mechanical property relationships in AAFS paste at different levels are discussed in detail.

\subsection{Microstructure-mechanics relationship from Level 0 to Level I}

The combination of nanoindentation, NMR and FTIR test results provides a strong evidence that the microscopic performance of AAFS paste at Level I is determined by two factors that occur at different scales: (1) the physical chemistry within solid gel particles at Level 0 , and (2) the gel porosity within gel matrix at Level I. These two characteristics determine the elastic modulus of different phases in gel matrix. As seen in Fig. 16, the distinction of elastic modulus between different phases is clear and follows an order of N-A-S-H gels $<$ N-C-AS-H gels $<$ C-A-S-H gels < unreacted slag $<$ unreacted fly ash.

Regarding the first factor, previous studies have noted that the nanostructure and chemical composition of solid gel have strong connections with its elastic modulus [101]. Generally, the elastic modulus of solid gel with crystalline structure (order structure) is obviously higher than that of the solid gel with amorphous structure (disorder structure) [101]. The implication is that the level of structural disorder would determine the elastic modulus of solid gel. Thus, the unreacted particles with the highest elastic modulus might be attributed to their compact nonactivated crystal solid. The unreacted fly ash has the highest elastic modulus (above $70 \mathrm{GPa}$ ), followed by unreacted slag, the elastic modulus of which is around $50 \mathrm{GPa}$. Regarding the reaction products, the occurrence of crystalline phase can be observed in C-A-S$\mathrm{H}$ gels of AAS [82], while there is almost none in N-A-S-H gels of AAF cured at ambient temperature [102]. This suggests that the C-A-S-H gels with a high elastic modulus of around $30 \mathrm{GPa}$ can be ascribed to their comparatively low level of structural disorder, while the N-A-S-H gels with a low elastic modulus of around $10 \mathrm{GPa}$ are highly related to their high level of structural disorder. The N-C-A-S-H gels with a middle elastic modulus of around $20 \mathrm{GPa}$ between N-A-S-H gels and C-A-S-H gels are associated with their middle level of structural disorder. The Ca-substituted N-A-S-H gels (N-C-A-S-H gels) may have a mineral feature between N-A-S-H gels and C-A-S-H gels, which retain the original 3D aluminosilicate framework structure but tend to have a similar composition with C-A-S-H gels [36].

Regarding the second factor, previous research has shown that gel porosity would directly affect the micromechanical properties of gel matrix at Level I [34]. Depending on the distinction of porosity, the C-S$\mathrm{H}$ gels in PC paste can be divided into two types: low density and high density [103]. It was reported that the low-density C-S-H gels have a relatively low elastic modulus due to their high porosity [104]. The high-density C-S-H gels have a comparatively high elastic modulus because of their densely packed structure and low porosity [104]. This indicates that gel porosity would determine the elastic modulus of gel matrix. Therefore, the difference of elastic modulus between C-A-S-H gels, N-A-S-H gels and N-C-A-S-H gels might be also ascribed to their different gel porosity. It was found that the C-A-S-H gels in AAFS paste have a similar structure with high-density C-S-H gels in PC paste [12]. This implies that the C-A-S-H gels also have a less porous structure, leading to a high elastic modulus. Regarding the N-A-S-H gels, it was reported that they have similar mechanical properties to the low-density C-S-H gels in PC paste [98]. This suggests that the N-A-S-H gels with low elastic modulus might also relate to the relatively high porosity, which is probably a result of their syneresis process [22]. The syneresis of N-A-S-H gels would cause the expulsion of entrained water and

Table 6

Elastic modulus (GPa) and volume fraction of individual solid phases in AAFS paste at different curing ages.

\begin{tabular}{|c|c|c|c|c|}
\hline Phases & $1-\mathrm{d}$ & $3-d$ & $7-d$ & $28-d$ \\
\hline A. N-A-S-H gels & $11.96 \pm 1.42(65.01 \%)$ & $10.66 \pm 0.10(63.44 \%)$ & $12.57 \pm 0.17(54.76 \%)$ & $12.22 \pm 0.17(77.98 \%)$ \\
\hline B. N-C-A-S-H gels & $18.99 \pm 3.44(15.24 \%)$ & $21.45 \pm 0.22(16.62 \%)$ & $21.40 \pm 0.34(37.72 \%)$ & $22.72 \pm 1.13(9.43 \%)$ \\
\hline C. C-A-S-H gels & $28.02 \pm 2.79(8.89 \%)$ & $34.53 \pm 0.28(14.79 \%)$ & $33.06 \pm 0.37(3.28 \%)$ & $34.94 \pm 0.57(12.59 \%)$ \\
\hline D. Unreacted slag & $49.75 \pm 0.69(7.53 \%)$ & $49.14 \pm 0.69(3.43 \%)$ & $48.20 \pm 0.30(2.48 \%)$ & - \\
\hline E. Unreacted fly ash & $78.68 \pm 0.52(3.33 \%)$ & $74.70 \pm 0.97(1.72 \%)$ & $70.69 \pm 0.94(1.76 \%)$ & - \\
\hline
\end{tabular}


Table 7

Statistical significance of elastic modulus between N-A-S-H gels (A), N-C-A-S-H gels (B) and C-A-S-H gels (C).

\begin{tabular}{llrll}
\hline Curing age (d) & Groups & $F$-value & $p$-value & Significance \\
\hline 1 & A\&B & 19.86 & $1.51 \times 10^{-5}$ & $* *$ \\
& B\&C & 33.51 & $5.95 \times 10^{-8}$ & $* *$ \\
& A\&C & 101.06 & 0 & $* * *$ \\
3 & A\&B & 32.77 & $4.82 \times 10^{-8}$ & $* * *$ \\
& B\&C & 54.02 & $3.86 \times 10^{-11}$ & $* * *$ \\
7 & A\&C & 198.89 & 0 & $* * *$ \\
& A\&B & 16.87 & $6.03 \times 10^{-5}$ & $* *$ \\
& B\&C & 53.69 & $5.03 \times 10^{-11}$ & $* *$ \\
& A\&C & 144.78 & 0 & $* * *$ \\
& A\&B & 44.69 & $3.79 \times 10^{-10}$ & $* *$ \\
& B\&C & 87.70 & $4.11 \times 10^{-15}$ & $* *$ \\
& A\&C & 416.56 & 0 & $* *$
\end{tabular}

** Strong significant difference.

Table 8

Statistical significance of elastic modulus between unreacted fly ash and slag.

\begin{tabular}{llll}
\hline Curing age (d) & $F$-value & $p$-value & Significance \\
\hline 1 & 35.95 & $1.45 \times 10^{-5}$ & $* *_{*}^{* *}$ \\
3 & 21.44 & $4.71 \times 10^{-4}$ & $*_{*}^{*}$ \\
7 & 30.80 & $5.56 \times 10^{-5}$ & $*_{*}^{*}$ \\
\hline
\end{tabular}

** Strong significant difference.

produce gel shrinkage, which would consequently lead to a high porosity [98]. The N-C-A-S-H gels with middle elastic modulus among the reaction products are possibly associated with their middle level of porosity.

In addition, the change in chemical composition and internal structure of solid gel particles at Level 0 would affect the evolution of elastic modulus of individual phases at Level I. As can be seen in Fig. 16 that the elastic modulus of N-A-S-H gels is stable at 11-12 GPa during the curing ages between $1 \mathrm{~d}$ and $28 \mathrm{~d}$, while the elastic moduli of N-C-A$\mathrm{S}-\mathrm{H}$ gels and C-A-S-H gels are increased steadily from $19 \mathrm{GPa}$ to $23 \mathrm{GPa}$ and from $28 \mathrm{GPa}$ to $35 \mathrm{GPa}$, respectively. Meanwhile, the elastic moduli of unreacted slag and fly ash are decreased steadily. According to the NMR analysis presented in Table 3, the chemical composition of N-A-S$\mathrm{H}$ gels is stable during the curing process, in which the $\mathrm{Al} / \mathrm{Si}$ ratio is steady at around 0.5 . Such stable composition might be associated with their constant elastic modulus. Besides, it can be seen from the FTIR results in Fig. 7 that the position of the main band for reaction products in AAFS paste (i.e. $980 \mathrm{~cm}^{-1}$ ) is at lower wavenumber than that in AAF paste based solely on fly ash (i.e. $1020 \mathrm{~cm}^{-1}$ ), indicating that the presence of Ca released from slag would affect the formation of N-A-S-H gels [9]. The presence of Ca tends to hinder the crystallization of N-A-S$\mathrm{H}$ gels and leads to a high level of structural disorder, leading to a relatively low elastic modulus of N-A-S-H gels [13]. In comparison, the change in chemical composition of C-A-S-H gels is obvious, where the $\mathrm{Al} / \mathrm{Si}$ ratio is increased significantly from 0.29 to 0.40 . This suggests that the silicate tetrahedron of C-A-S-H solid gel particles would be substituted by the aluminate species during the reaction process, which is consistent with the FTIR observations. As shown in Fig. 7, the band of Al-O-Si bonds within C-A-S-H gels becomes sharper with the increase of curing ages, implying the higher $\mathrm{Al}$ content within the silica network of C-A-S-H gels [86]. In addition, the internal structure of C-A-S-H gels is also changed apparently during the curing process. As seen in Fig. 6, the amount of $\mathrm{Q}^{1}$ sites is decreased dramatically from $18.15 \%$ to $7.09 \%$ as the curing age increases from $1 \mathrm{~d}$ to $28 \mathrm{~d}$, while the content of $\mathrm{Q}^{2}(1 \mathrm{Al})$ sites is increased from $25.41 \%$ to $28.06 \%$. These structural changes would increase the $\mathrm{Q}$ sites connectivity, the cross-linking degree and the crystalline order [105]. Furthermore, the packing density of C-A-S$\mathrm{H}$ gels might be also changed with the increase of curing age. It is known that the C-A-S-H particles are linked together by condensation $[41,106]$ and the packing efficiency at the surface of particles would be improved with the progress of reaction, giving a high value of density and filling the pore space. These multiple effects known as the chemical composition and internal structure in C-A-S-H gels would consequently improve their elastic modulus. Furthermore, the internal structure of $\mathrm{N}$ $\mathrm{C}-\mathrm{A}-\mathrm{S}-\mathrm{H}$ gels is also altered during the reaction process. The silicate tetrahedron of N-C-A-S-H solid gel particles would be also substituted by the aluminate species during reaction process, corresponding to the increase of $\mathrm{Al} / \mathrm{Si}$ ratio of $\mathrm{N}-\mathrm{C}-\mathrm{A}-\mathrm{S}-\mathrm{H}$ gels from 0.20 to 0.29 . These structural changes are related to the improvement of elastic modulus in $\mathrm{N}-\mathrm{C}-\mathrm{A}-\mathrm{S}-\mathrm{H}$ gels. The slight decline of elastic moduli of unreacted slag and fly ash can be explained by the decrease of particle size due to the artificial influence in sample preparation. The slag and fly ash particles with a lower size would substantially have a higher surface-to-volume ratio, which may promote the precipitation of reaction products on the surface of these particles. The relatively soft matrix (i.e. reaction products) attached on the surface of particles would change the load-displacement behaviour of particles during indentation loading, and consequently affect the elastic moduli of unreacted slag and fly ash.

Moreover, there are transformations between different reaction products during the reaction process, which would affect the evolution of their elastic moduli. As seen in Fig. 17, the volume fraction of N-A-S$\mathrm{H}$ gels is decreased from $65.01 \%$ to $54.76 \%$ at early $7 \mathrm{~d}$, while the

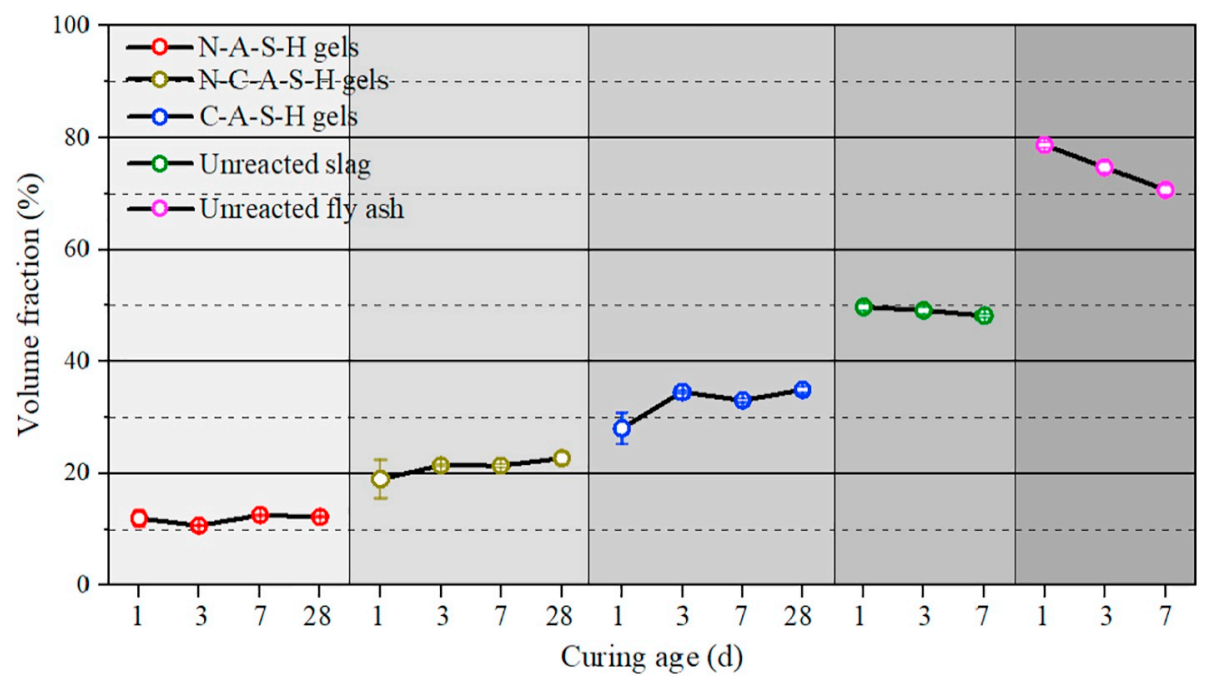

Fig. 16. Elastic modulus of different phases in AAFS paste at different curing ages. 


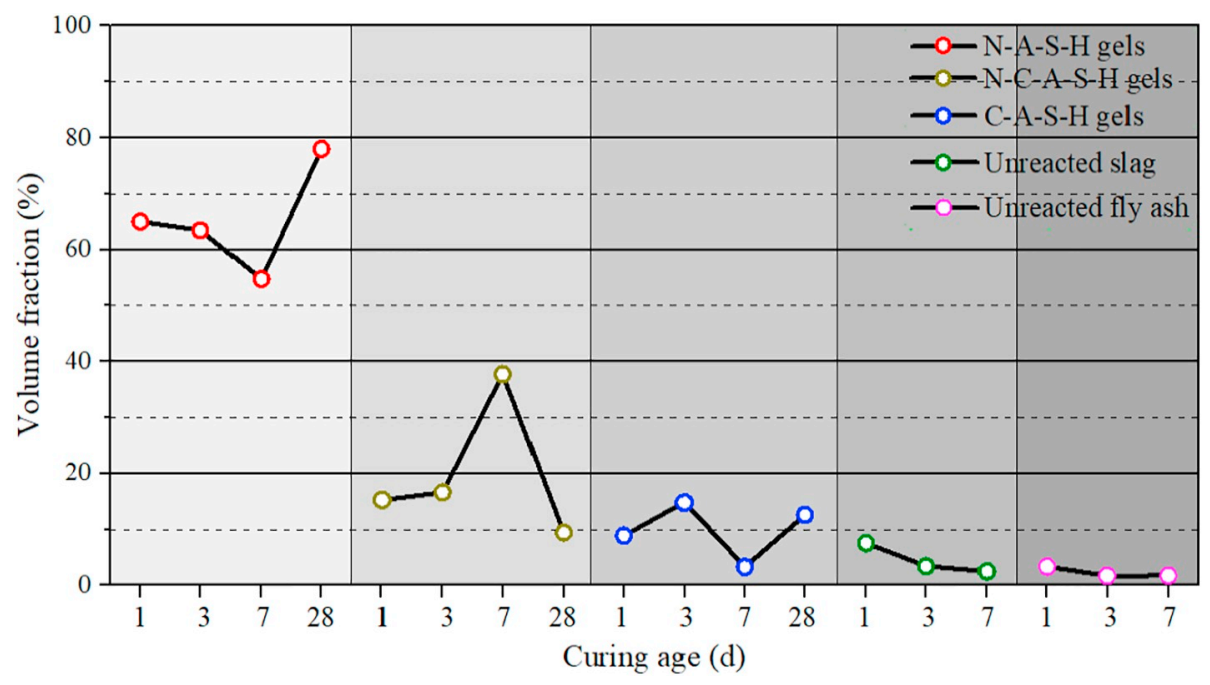

Fig. 17. Volume fraction of elastic modulus of different phases in AAFS paste at different curing ages.

Table 9

Bulk modulus (K) and shear modulus $(G)$ of individual solid phases in AAFS paste at different curing ages (GPa).

\begin{tabular}{|c|c|c|c|c|c|c|c|c|}
\hline \multirow[t]{2}{*}{ Phases } & \multicolumn{2}{|l|}{$1-\mathrm{d}$} & \multicolumn{2}{|l|}{ 3-d } & \multicolumn{2}{|l|}{ 7-d } & \multicolumn{2}{|l|}{$28-d$} \\
\hline & $\mathrm{K}$ & $\mathrm{G}$ & $\mathrm{K}$ & G & $\mathrm{K}$ & G & $\mathrm{K}$ & G \\
\hline A. N-A-S-H gels & 6.64 & 4.98 & 5.92 & 4.44 & 6.98 & 5.24 & 6.79 & 5.09 \\
\hline $\begin{array}{l}\text { B. N-C-A-S-H } \\
\text { gels }\end{array}$ & 10.55 & 7.91 & 11.92 & 8.94 & 11.89 & 8.92 & 12.62 & 9.47 \\
\hline C. C-A-S-H gels & 15.57 & 11.68 & 19.18 & 14.39 & 18.37 & 13.78 & 19.41 & 14.56 \\
\hline $\begin{array}{l}\text { D. Unreacted } \\
\text { slag }\end{array}$ & 27.64 & 20.73 & 27.30 & 20.48 & 26.78 & 20.08 & - & - \\
\hline $\begin{array}{l}\text { E. Unreacted fly } \\
\text { ash }\end{array}$ & 43.71 & 32.78 & 41.50 & 31.13 & 39.27 & 29.45 & - & - \\
\hline
\end{tabular}

\section{Table 10}

Effective elastic modulus ( $\left.E_{\text {eff }}\right)$, effective bulk modulus $\left(K_{\text {eff }}\right)$ and effective shear modulus $\left(G_{e f f}\right)$ of AAFS paste at different curing ages (GPa).

\begin{tabular}{lrrrr}
\hline & \multicolumn{1}{c}{ 1-d } & \multicolumn{1}{c}{ 3-d } & \multicolumn{1}{c}{ 7-d } & \multicolumn{1}{c}{28 -d } \\
\hline$E_{\text {eff }}$ & 16.13 & 15.33 & 16.80 & 14.69 \\
$K_{\text {eff }}$ & 8.96 & 8.51 & 9.33 & 8.16 \\
$G_{\text {eff }}$ & 6.72 & 6.39 & 7.00 & 6.12 \\
\hline
\end{tabular}

volume fraction of N-C-A-S-H gels is increased from $15.24 \%$ to $37.72 \%$. This suggests that part of N-A-S-H gels have been transformed to N-C-A$\mathrm{S}$-H gels via interchanging between $\mathrm{Ca}$ and $\mathrm{Na}$, due to the strong polarising power of the aqueous $\mathrm{Ca}$ ion relative to the $\mathrm{Na}$ ion [36]. The substitution of Ca would drive the precipitation of N-C-A-S-H solid gel and contribute to the development of a comparable structure to C-A-S-H solid gel, leading to a higher elastic modulus $[9,36]$. At later curing ages (7-28 d), the volume fraction of N-A-S-H gels increases significantly from $54.76 \%$ to $77.98 \%$, which implies that the effects of mobile Ca ion on the formation of N-A-S-H gels become less. This is mainly because of the reduction of free Ca releasing from slag due to the low content of slag ( $25 \%$ of the total precursors). At the same time, the volume fraction of N-C-A-S-H gels is decreased from $37.72 \%$ to $9.43 \%$, while that of C-A-S-H gels is increased from $3.28 \%$ to $12.59 \%$. This indicates the transformation between N-C-A-S-H gels and C-A-S-H gels, where the Na in N-C-A-S-H gels is continually replaced by $\mathrm{Ca}$ and eventually lead to the formation of C-A-S-H gels [107]. However, it is worth noting that the transformation from N-C-A-S-H gels to N-A-S-H gels is difficult to happen due to the strong binding of Ca within N-C-A-S-H gels. During the formation of N-C-A-S-H gels, the polarising effect of Ca ion would distort the Si-O-Al bonds and subsequently form the stable $\mathrm{Si}-\mathrm{O}-\mathrm{Ca}$ bonds [108]. These stable Si-O-Ca bonds are difficult to be distorted by the presence of $\mathrm{Na}$ ion, because the polarising power of $\mathrm{Na}$ ion is weaker than that of $\mathrm{Ca}$ ion.

\subsection{Microstructure-mechanics relationship from Level I to Level II}

According to the experimental results obtained from nanoindentation, MIP and SEM tests as well as the theoretical results based on the self-consistent continuum micromechanics model, the macroscopic performance of AAFS paste at Level II is dominated by two factors that exist at different scales: (1) the microscopic properties of reaction products at Level I, and (2) the characteristics of pore structure at Level II [26].

Regarding the reaction products, the micromechanical properties of reaction products are expected to determine the macroscopic performance of AAFS paste as the reaction products dominate the volumetric proportion of paste matrix. As shown in Fig. 18a, the overall elastic modulus of reaction products is fluctuant between $16.62 \mathrm{GPa}$ and $17.62 \mathrm{GPa}$ as the curing age increases from $1 \mathrm{~d}$ to $28 \mathrm{~d}$. This phenomenon is similar to the development of elastic modulus in N-A-S-H gels but is different compared with the development in N-C-A-S-H gels and C-A-S-H gels. The elastic modulus of N-A-S-H gels is fluctuant between $11 \mathrm{GPa}$ and $12 \mathrm{GPa}$. Nevertheless, the elastic moduli of N-C-A-S$\mathrm{H}$ gels and C-A-S-H gels are increased from $19 \mathrm{GPa}$ to $23 \mathrm{GPa}$ and from $28 \mathrm{GPa}$ to $35 \mathrm{GPa}$, respectively. This suggests that the overall elasticity of reaction products is primarily represented by the elastic moduli of $\mathrm{N}$ A-S-H gels. It is mainly because of the existence of high-volume N-A-S-H gels, in which their volume occupies $54.76-77.98 \%$ of AAFS paste (see Fig. 17). Furthermore, it can be seen from the data in Table 10 that the overall homogenised elastic modulus of AAFS paste is also fluctuant during the curing process. The effective elastic modulus and bulk modulus of AAFS paste fluctuate in the range of 14.69-16.80 GPa and 8.16-9.33 GPa, respectively, while the effective shear modulus is stable at 6.12-7.00 GPa. This indicates that the macroscopic elasticity of AAFS paste has a strong relation with the elasticity of reaction products. Besides, since the N-A-S-H gels dominate the volumetric proportions of reaction products, their contribution to the macroscopic elastic performance is therefore significant. It implies that the volume fraction of different reaction products would also affect the macroscopic elasticity of AAFS paste. However, the connection between the hardness of reaction products and macroscopic strength of AAFS paste is not strong. As seen in Fig. 18b, the overall hardness of reaction products is increased slightly from $1.02 \mathrm{GPa}$ to $1.45 \mathrm{GPa}$ with the increase of curing 
(a)

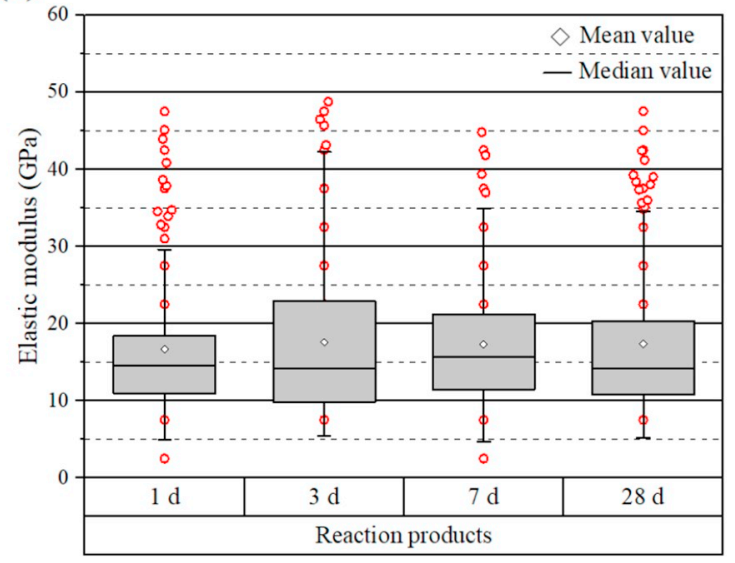

(b)

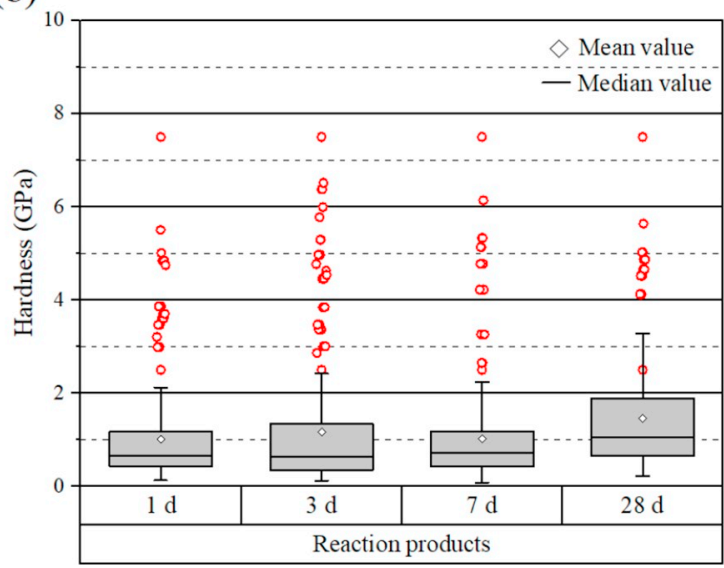

Fig. 18. Elastic modulus and hardness of reaction products in AAFS paste at different curing ages.

age from $1 \mathrm{~d}$ to $28 \mathrm{~d}$, which is different compared with the rigorous increase of compressive strength in AAFS paste. The compressive strength is increased dramatically from $18.5 \mathrm{MPa}$ to $53.7 \mathrm{MPa}$ with increasing curing age from $1 \mathrm{~d}$ to $28 \mathrm{~d}$ [47].

Regarding the pore structure, the change in pore size and porosity would directly affect the development of macroscopic mechanical properties of AAFS paste [46]. As seen in Fig. 11, the total porosity of AAFS paste is decreased dramatically from about $28 \%$ to $10 \%$ at early curing ages $(<7 \mathrm{~d})$. Meantime, the pore size is refined continuously during these early ages. Afterwards, the pore structure is changed slightly during the later curing ages between $7 \mathrm{~d}$ and $28 \mathrm{~d}$. The developing trend of pore structure is similar to that of compressive strength in AAFS paste. According to the authors' previous research [47], the compressive strength increases significantly from $18.5 \mathrm{MPa}$ to $39.8 \mathrm{MPa}$ between $1 \mathrm{~d}$ and $7 \mathrm{~d}$, while it increases less significantly from $39.8 \mathrm{MPa}$ to $53.7 \mathrm{MPa}$ between $7 \mathrm{~d}$ and $28 \mathrm{~d}$. This implies that the refinement of pore structure might be associated with the improvement of compressive strength, which is consistent with other research [34,46]. Nevertheless, the effects of pore structure on the macroscopic elasticity of paste matrix are less significance. The effective elastic modulus, bulk modulus and shear modulus of AAFS paste are fluctuant during the curing process (see Table 10), which are different compared with the continued refinement of pore structure (see Fig. 11).

The discussion presented above demonstrates that the macroscopic performance of AAFS paste is highly dependent on the microscopic properties of reaction products and the features of pore structure. The macroscopic elasticity is primarily influenced by the elasticity of reaction products and their relative volumetric proportions, while the macroscopic strength is mainly determined by the porosity and pore size distribution.

\section{Conclusions}

In this paper, a series of tests including NMR, FTIR, MIP, SEM and nanoindentation were carried out to investigate the microstructure and micromechanical properties of AAFS paste cured at ambient temperature from nano-scale to micro-scale. The multiscale features of AAFS paste are clarified according to three scales: solid gel particle at Level 0 , gel matrix at Level I, and AAFS paste at Level II. According to the experimental results, the main conclusions can be drawn as follows:

- The microscopic properties of AAFS paste at Level I are dependent on the structural disorder level of solid gel particles at Level 0 and the porosity of gel matrix at Level I. The solid phase with low level of structural disorder and gel porosity tends to have a high microscopic mechanical property. Here, the elastic modulus of individual solid phases follows an order of N-A-S-H gels $<$ N-C-A-S-H gels $<$ C-A-S-H gels $<$ unreacted slag $<$ unreacted fly ash. The unreacted fly ash and slag with highly dense nonactivated crystal solid have a higher elastic modulus than the reaction products. Due to their relatively low level of structural disorder and gel porosity, the C-A-S-H gels have the highest elastic modulus among the reaction products, followed by N-C-A-S-H gels and N-A-S-H gels.

- The change in chemical composition and internal structure of solid gel particles at Level 0 would affect the evolution of elastic modulus of solid phase at Level I. In detail: (1) The elastic modulus of N-A-S$\mathrm{H}$ gels is stable at 11-12 GPa regardless of curing age. It is associated with the stable chemical composition of N-A-S-H solid gel particles, in which the $\mathrm{Al} / \mathrm{Si}$ ratio is steady at 0.5 . Meanwhile, the presence of Ca released from slag would hinder the crystallization of N-A-S-H gels, which would lead to a high structural disorder level and a low elastic modulus. (2) The elastic modulus of C-A-S-H gels is increased from $28 \mathrm{GPa}$ to $35 \mathrm{GPa}$ as the curing age increases from $1 \mathrm{~d}$ to $28 \mathrm{~d}$, which can be attributed to the increase of packing density, crystalline structure and cross-linking degree. These changes in structure are ascribed to the substitute of aluminate species, in which the $\mathrm{Al}$ / $\mathrm{Si}$ ratio is increased from 0.29 to 0.40 . (3) The increase of elastic modulus of N-C-A-S-H gels from $19 \mathrm{GPa}$ to $23 \mathrm{GPa}$ is associated with their structure arrangement. During the reaction process, part of $\mathrm{Na}$ within N-C-A-S-H solid gel are replaced by $\mathrm{Ca}$, which would drive the precipitation of N-C-A-S-H solid gel and contribute to the development of a structure comparable to C-A-S-H solid gel.

- The macroscopic performance of AAFS paste at Level II is highly dependent on the microscopic properties of reaction products at Level I and the characteristics of pore structure at Level II. The elasticity of reaction products and their relative volumetric proportions mainly determine the macroscopic elasticity, while the porosity and pore size distribution play a dominant role in affecting the macroscopic strength.

Nevertheless, it is worth noting that the relationship between microstructure and micromechanical properties of AAFS paste might be reshaped by the change of mix proportions, as the change of mix proportions would affect the reaction process and lead to some changes in the chemical composition and internal structure of reaction products. Consequently, the micromechanical properties of gel matrix would be altered. Therefore, it is vital to consider the effects of different mix proportions on the micromechanical properties of AAFS paste. This is a subject of ongoing work and will be presented in a future publication. 


\section{CRediT authorship contribution statement}

Guohao Fang:Conceptualization, Methodology, Investigation, Data curation, Visualization, Writing - original draft.Mingzhong Zhang:Conceptualization, Funding acquisition, Project administration, Supervision, Writing - review \& editing.

\section{Declaration of competing interest}

The authors declare no conflict of interest.

\section{Acknowledgements}

The authors gratefully acknowledge the financial support from the Engineering and Physical Sciences Research Council (EPSRC), UK under Grant No. EP/R041504/1 and the Royal Society, UK under Award No. IEC $\backslash N S F C \backslash 191417$ as well as the State Key Laboratory of Silicate Materials for Architectures (Wuhan University of Technology), China under Award No. SYSJJ2018-08. The financial support provided by University College London (UCL) and China Scholarship Council (CSC) to the first author is gratefully acknowledged.

\section{References}

[1] C. Shi, A.F. Jiménez, A. Palomo, New cements for the 21st century: the pursuit of an alternative to Portland cement, Cem. Concr. Res. 41 (2011) 750-763.

[2] X. Zhuang, L. Chen, S. Komarneni, C. Zhou, D. Tong, H. Yang, W. Yu, H. Wang, Fly ash-based geopolymer: clean production, properties and applications, J. Clean. Prod. 125 (2016) 253-267.

[3] J.L. Provis, Alkali-activated materials, Cem. Concr. Res. 114 (2018) 40-48.

[4] Y. Fan, S. Yin, Z. Wen, J. Zhong, Activation of fly ash and its effects on cement properties, Cem. Concr. Res. 29 (1999) 467-472.

[5] K. Somna, C. Jaturapitakkul, P. Kajitvichyanukul, P. Chindaprasirt, NaOH-activated ground fly ash geopolymer cured at ambient temperature, Fuel 90 (2011) 2118-2124.

[6] F. Puertas, S. Martínez-Ramírez, S. Alonso, T. Vázquez, Alkali-activated fly ash/ slag cements: strength behaviour and hydration products, Cem. Concr. Res. 30 (2000) 1625-1632.

[7] N.K. Lee, H.K. Lee, Reactivity and reaction products of alkali-activated, fly ash/ slag paste, Constr. Build. Mater. 81 (2015) 303-312.

[8] J. Shang, J. Dai, T. Zhao, S. Guo, P. Zhang, B. Mu, Alternation of traditional cement mortars using fly ash-based geopolymer mortars modified by slag, J. Clean. Prod. 203 (2018) 746-756.

[9] I. Ismail, S.A. Bernal, J.L. Provis, R. San Nicolas, S. Hamdan, J.S.J. van Deventer, Modification of phase evolution in alkali-activated blast furnace slag by the incorporation of fly ash, Cem. Concr. Compos. 45 (2014) 125-135.

[10] A. Fernández-Jiménez, A. Palomo, M. Criado, Microstructure development of alkali-activated fly ash cement: a descriptive model, Cem. Concr. Res. 35 (2005) 1204-1209.

[11] S.A. Bernal, J.L. Provis, B. Walkley, R. San Nicolas, J.D. Gehman, D.G. Brice, A.R. Kilcullen, P. Duxson, J.S.J. van Deventer, Gel nanostructure in alkali-activated binders based on slag and fly ash, and effects of accelerated carbonation, Cem. Concr. Res. 53 (2013) 127-144.

[12] F. Puertas, M. Palacios, H. Manzano, J.S. Dolado, A. Rico, J. Rodríguez, A model for the C-A-S-H gel formed in alkali-activated slag cements, J. Eur. Ceram. Soc. 31 (2011) 2043-2056

[13] H. Ye, A. Radlińska, Fly ash-slag interaction during alkaline activation: influence of activators on phase assemblage and microstructure formation, Constr. Build. Mater. 122 (2016) 594-606.

[14] R.R. Lloyd, J.L. Provis, J.S.J. van Deventer, Microscopy and microanalysis of inorganic polymer cements. 2: the gel binder, J. Mater. Sci. 44 (2009) 620-631.

[15] P. Nath, P.K. Sarker, Effect of GGBFS on setting, workability and early strength properties of fly ash geopolymer concrete cured in ambient condition, Constr. Build. Mater. 66 (2014) 163-171.

[16] M. Marcin, M. Sisol, I. Brezani, Effect of slag addition on mechanical properties of Fly ash based Geopolymers, Procedia Eng. 151 (2016) 191-197.

[17] P.S. Deb, P. Nath, P.K. Sarker, The effects of ground granulated blast-furnace slag blending with fly ash and activator content on the workability and strength properties of geopolymer concrete cured at ambient temperature, Mater. Des. 62 (2014) 32-39.

[18] B. Singh, M.R. Rahman, R. Paswan, S.K. Bhattacharyya, Effect of activator concentration on the strength, ITZ and drying shrinkage of fly ash/slag geopolymer concrete, Constr. Build. Mater. 118 (2016) 171-179.

[19] T. Phoo-ngernkham, A. Maegawa, N. Mishima, S. Hatanaka, P. Chindaprasirt, Effects of sodium hydroxide and sodium silicate solutions on compressive and shear bond strengths of FA-GBFS geopolymer, Constr. Build. Mater. 91 (2015) 1-8.

[20] S. Puligilla, P. Mondal, Role of slag in microstructural development and hardening of fly ash-slag geopolymer, Cem. Concr. Res. 43 (2013) 70-80.

[21] G. Fang, W.K. Ho, W. Tu, M. Zhang, Workability and mechanical properties of alkali-activated fly ash-slag concrete cured at ambient temperature, Constr. Build. Mater. 172 (2018) 476-487.

[22] V. Šmilauer, P. Hlaváček, F. Škvára, R. Šulc, L. Kopecký, J. Němeček, Micromechanical multiscale model for alkali activation of fly ash and metakaolin, J. Mater. Sci. 46 (2011) 6545-6555.

[23] R.J. Thomas, B.S. Gebregziabiher, A. Giffin, S. Peethamparan, Micromechanical properties of alkali-activated slag cement binders, Cem. Concr. Compos. 90 (2018) 241-256.

[24] C. Hu, Z. Li, A review on the mechanical properties of cement-based materials measured by nanoindentation, Constr. Build. Mater. 90 (2015) 80-90.

[25] J.J. Hughes, P. Trtik, Micro-mechanical properties of cement paste measured by depth-sensing nanoindentation: a preliminary correlation of physical properties with phase type, Mater. Charact. 53 (2004) 223-231.

[26] G. Constantinides, F.-J. Ulm, The effect of two types of C-S-H on the elasticity of cement-based materials: results from nanoindentation and micromechanical modeling, Cem. Concr. Res. 34 (2004) 67-80.

[27] N.X. Randall, M. Vandamme, F.-J. Ulm, Nanoindentation analysis as a two-dimensional tool for mapping the mechanical properties of complex surfaces, J. Mater. Res. 24 (2011) 679-690.

[28] G. Constantinides, F.-J. Ulm, K. Van Vliet, On the use of nanoindentation for cementitious materials, Mater. Struct. 36 (2003) 191-196.

[29] J. Němeček, V. Šmilauer, L. Kopecký, Nanoindentation characteristics of alkaliactivated aluminosilicate materials, Cem. Concr. Compos. 33 (2011) 163-170.

[30] M. Khedmati, H. Alanazi, Y.-R. Kim, G. Nsengiyumva, S. Moussavi, Effects of $\mathrm{Na}_{2} \mathrm{O} / \mathrm{SiO}_{2}$ molar ratio on properties of aggregate-paste interphase in fly ash-based geopolymer mixtures through multiscale measurements, Constr. Build. Mater. 191 (2018) 564-574.

[31] S. Das, P. Yang, S.S. Singh, J.C.E. Mertens, X. Xiao, N. Chawla, N. Neithalath, Effective properties of a fly ash geopolymer: synergistic application of X-ray synchrotron tomography, nanoindentation, and homogenization models, Cem. Concr. Res. 78 (2015) 252-262.

[32] Y. Ma, G. Ye, J. Hu, Micro-mechanical properties of alkali-activated fly ash evaluated by nanoindentation, Constr. Build. Mater. 147 (2017) 407-416.

[33] M. Nedeljković, B. Šavija, Y. Zuo, M. Luković, G. Ye, Effect of natural carbonation on the pore structure and elastic modulus of the alkali-activated fly ash and slag pastes, Constr. Build. Mater. 161 (2018) 687-704.

[34] J. Tatar, C.R. Taylor, H.R. Hamilton, A multiscale micromechanical model of adhesive interphase between cement paste and epoxy supported by nanomechanical evidence, Compos. Part B 172 (2019) 679-689.

[35] F.-J. Ulm, A. Delafargue, G. Constantinides, Experimental Microporomechanics, in: L. Dormieux, F.-J. Ulm (Eds.), Applied Micromechanics of Porous Materials, Springer Vienna, Vienna, 2005, pp. 207-288.

[36] I. Garcia-Lodeiro, A. Palomo, A. Fernández-Jiménez, D.E. Macphee, Compatibility studies between N-A-S-H and C-A-S-H gels. Study in the ternary diagram Na2O-CaO-Al2O3-SiO2-H2O, Cem. Concr. Res. 41 (2011) 923-931.

[37] G. Constantinides, Invariant Mechanical Properties of Calcium-Silicate-Hydrates (C-S-H) in Cement-Based Materials: Instrumented Nanoindentation and Microporomechanical Modeling ( $\mathrm{PhD}$ thesis), Department of Civil and Environmental Engineering, Massachusetts Institute of Technology, 2006.

[38] A. Palomo, M.W. Grutzeck, M.T. Blanco, Alkali-activated fly ashes: a cement for the future, Cem. Concr. Res. 29 (1999) 1323-1329.

[39] J.L. Provis, S.A. Bernal, Geopolymers and related alkali-activated materials, Annu. Rev. Mater. Res, 44 (2014) 299-327.

[40] J.E. Oh, Y. Jun, Y. Jeong, Characterization of geopolymers from compositionally and physically different class F fly ashes, Cem. Concr. Compos. 50 (2014) 16-26.

[41] A. Fernandez-Jimenez, F. Puertas, I. Sobrados, J. Sanz, Structure of calcium silicate hydrates formed in alkaline-activated slag: influence of the type of alkaline activator, J. Am. Ceram. Soc. 86 (2003) 1389-1394.

[42] A. Nikolov, I. Rostovsky, H. Nugteren, Geopolymer materials based on natural zeolite, Case Stud. Construction Mater. 6 (2017) 198-205.

[43] S.-D. Wang, K.L. Scrivener, Hydration products of alkali activated slag cement, Cem. Concr. Res. 25 (1995) 561-571.

[44] T. Yang, X. Yao, Z. Zhang, H. Wang, Mechanical property and structure of alkaliactivated fly ash and slag blends, J. Sustainable Cement-Based Mater. 1 (2012) $167-178$.

[45] G. Fang, H. Bahrami, M. Zhang, Mechanisms of autogenous shrinkage of alkaliactivated fly ash-slag pastes cured at ambient temperature within $24 \mathrm{~h}$, Constr. Build. Mater. 171 (2018) 377-387.

[46] A. Keulen, Q. Yu, S. Zhang, S. Grunewald, Effect of admixture on the pore structure refinement and enhanced performance of alkali-activated fly ash-slag concrete, Constr. Build. Mater. 162 (2018) 27-36.

[47] W. Tu, Y. Zhu, G. Fang, X. Wang, M. Zhang, Internal curing of alkali-activated fly ash-slag pastes using superabsorbent polymer, Cem. Concr. Res. 116 (2019) 179-190.

[48] O. Bernard, F.-J. Ulm, E. Lemarchand, A multiscale micromechanics-hydration model for the early-age elastic properties of cement-based materials, Cem. Concr. Res. 33 (2003) 1293-1309.

[49] F.J. Ulm, G. Constantinides, F.H. Heukamp, Is concrete a poromechanics materials? - a multiscale investigation of poroelastic properties, Mater. Struct. 37 (2004) 43-58.

[50] A. Zaoui, Continuum micromechanics: survey, J. Eng. Mech. 128 (2002) 808-816.

[51] B. Pichler, C. Hellmich, J. Eberhardsteiner, Spherical and acicular representation of hydrates in a micromechanical model for cement paste: prediction of early-age elasticity and strength, Acta Mech. 203 (2008) 137. 
[52] B. Pichler, C. Hellmich, Upscaling quasi-brittle strength of cement paste and mortar: a multi-scale engineering mechanics model, Cem. Concr. Res. 41 (2011) 467-476.

[53] G. Constantinides, F.-J. Ulm, The nanogranular nature of C-S-H, J. Mechanics Physics Solids 55 (2007) 64-90.

[54] M. Talha Junaid, O. Kayali, A. Khennane, J. Black, A mix design procedure for low calcium alkali activated fly ash-based concretes, Constr. Build. Mater. 79 (2015) 301-310.

[55] BS EN 197-1:2011, Cement Part 1: Composition, Specifications and Conformity Criteria for Common Cements, BSI Standards Publication, 2011.

[56] BS EN 206:2013 + A1:2016, Concrete — Specification, Performance, Production and Conformity, BSI Standards Publication, 2016.

[57] J.G. Jang, N.K. Lee, H.K. Lee, Fresh and hardened properties of alkali-activated fly ash/slag pastes with superplasticizers, Constr. Build. Mater. 50 (2014) 169-176.

[58] N.K. Lee, H.K. Lee, Setting and mechanical properties of alkali-activated fly ash/ slag concrete manufactured at room temperature, Constr. Build. Mater. 47 (2013) 1201-1209.

[59] S. Luo, M. Liu, L. Yang, J. Chang, Effects of drying techniques on the crystal structure and morphology of ettringite, Constr. Build. Mater. 195 (2019) 305-311.

[60] J. Zhang, G.W. Scherer, Comparison of methods for arresting hydration of cement, Cem. Concr. Res. 41 (2011) 1024-1036.

[61] G. Fang, M. Zhang, The evolution of interfacial transition zone in alkali-activated fly ash-slag concrete, Cem. Concr. Res. 129 (2020) 105963.

[62] X. Gao, Q. Yu, H.J.H. Brouwers, Apply ${ }^{29} \mathrm{Si},{ }^{27} \mathrm{Al}$ MAS NMR and selective dissolution in identifying the reaction degree of alkali activated slag-fly ash composites, Ceram. Int. 43 (2017) 12408-12419.

[63] X. Chen, G. Zhu, M. Zhou, J. Wang, Q. Chen, Effect of organic polymers on the properties of slag-based Geopolymers, Constr. Build. Mater. 167 (2018) 216-224.

[64] S. Wang, K.L. Scrivener, ${ }^{29} \mathrm{Si}$ and ${ }^{27} \mathrm{Al}$ NMR study of alkali-activated slag, Cem. Concr. Res. 33 (2003) 769-774.

[65] P.T. Durdziński, C.F. Dunant, M.B. Haha, K.L. Scrivener, A new quantification method based on SEM-EDS to assess fly ash composition and study the reaction of its individual components in hydrating cement paste, Cem. Concr. Res. 73 (2015) 111-122.

[66] S. Diamond, Mercury porosimetry: an inappropriate method for the measurement of pore size distributions in cement-based materials, Cem. Concr. Res. 30 (2000) $1517-1525$.

[67] H. Ma, Mercury intrusion porosimetry in concrete technology: tips in measurement, pore structure parameter acquisition and application, J. Porous. Mater. 21 (2014) 207-215.

[68] J. Kaufmann, R. Loser, A. Leemann, Analysis of cement-bonded materials by multicycle mercury intrusion and nitrogen sorption, J. Colloid Interface Sci. 336 (2009) $730-737$.

[69] J. Xiao, W. Li, Z. Sun, D.A. Lange, S.P. Shah, Properties of interfacial transition zones in recycled aggregate concrete tested by nanoindentation, Cem. Concr. Compos. 37 (2013) 276-292.

[70] C. Hu, Z. Li, Property investigation of individual phases in cementitious composites containing silica fume and fly ash, Cem. Concr. Compos. 57 (2015) 17-26.

[71] H. Buckle, Applications to other material properties, in: J.H. Westbrook, H. Conrad (Eds.), The Science of Hardness Testing and Its Applications, Ohio, 1973.

[72] C. Hu, Microstructure and mechanical properties of fly ash blended cement pastes, Constr. Build. Mater. 73 (2014) 618-625.

[73] W.C. Oliver, G.M. Pharr, An improved technique for determining hardness and elastic modulus using load and displacement sensing indentation experiments, $\mathrm{J}$. Mater. Res. 7 (2011) 1564-1583.

[74] X. Zhu, Y. Yuan, L. Li, Y. Du, F. Li, Identification of interfacial transition zone in asphalt concrete based on nano-scale metrology techniques, Mater. Des. 129 (2017) 91-102.

[75] R.J. Thomas, S. Peethamparan, Alkali-activated concrete: engineering properties and stress-strain behavior, Constr. Build. Mater. 93 (2015) 49-56.

[76] M. Sofi, J.S.J. van Deventer, P. Mendis, G.C. Lukey, Engineering properties of inorganic polymer concretes (IPCs), Cem. Concr. Res. 37 (2007) 251-257.

[77] P.S. Singh, T. Bastow, M. Trigg, Structural studies of geopolymers by ${ }^{29} \mathrm{Si}$ and ${ }^{27} \mathrm{Al}$ MAS-NMR, J. Mater. Sci. 40 (2005) 3951-3961.

[78] E. Lippmaa, M. Maegi, A. Samoson, G. Engelhardt, A.R. Grimmer, Structural studies of silicates by solid-state high-resolution silicon-29 NMR, J. Am. Chem. Soc. 102 (1980) 4889-4893.

[79] Á. Palomo, S. Alonso, A. Fernandez-Jiménez, I. Sobrados, J. Sanz, Alkaline activation of Fly ashes: NMR study of the reaction products, J. Am. Ceram. Soc. 87 (2004) 1141-1145.

[80] R.J. Myers, S.A. Bernal, R. San Nicolas, J.L. Provis, Generalized structural description of calcium-sodium Aluminosilicate hydrate gels: the cross-linked substituted Tobermorite model, Langmuir 29 (2013) 5294-5306.

[81] A.F. Abdalqader, F. Jin, A. Al-Tabbaa, Development of greener alkali-activated cement: utilisation of sodium carbonate for activating slag and fly ash mixtures, $\mathrm{J}$. Clean. Prod. 113 (2016) 66-75.

[82] M.B. Haha, B. Lothenbach, G. Le Saout, F. Winnefeld, Influence of slag chemistry on the hydration of alkali-activated blast-furnace slag — part I: effect of $\mathrm{MgO}$, Cem. Concr. Res. 41 (2011) 955-963.

[83] E. L'Hôpital, B. Lothenbach, G. Le Saout, D. Kulik, K. Scrivener, Incorporation of aluminium in calcium-silicate-hydrates, Cem. Concr. Res. 75 (2015) 91-103.

[84] G.n. Engelhardt, D. Michel, High-Resolution Solid-State NMR of Silicates and Zeolites, Wiley, Chichester, 1987.

[85] B. Walkley, R. San Nicolas, M.-A. Sani, J.D. Gehman, J.S.J. van Deventer, J.L. Provis, Synthesis of stoichiometrically controlled reactive aluminosilicate and calcium-aluminosilicate powders, Powder Technol. 297 (2016) 17-33.

[86] B. Walkley, R. San Nicolas, M.-A. Sani, G.J. Rees, J.V. Hanna, J.S.J. van Deventer, J.L. Provis, Phase evolution of C-(N)-A-S-H/N-A-S-H gel blends investigated via alkali-activation of synthetic calcium aluminosilicate precursors, Cem. Concr. Res. 89 (2016) 120-135.

[87] S.M. Park, H.R. Khalid, J.H. Seo, H.N. Yoon, H.M. Son, S.H. Kim, N.K. Lee, H.K. Lee, J.G. Jang, Pressure-induced Geopolymerization in alkali-activated Fly ash, Sustainability 10 (2018) 3538.

[88] R.T. Chancey, P. Stutzman, M.C.G. Juenger, D.W. Fowler, Comprehensive phase characterization of crystalline and amorphous phases of a class F fly ash, Cem. Concr. Res. 40 (2010) 146-156.

[89] A. Beran, D. Voll, H. Schneider, Dehydration and structural development of mullite precursors: an FTIR spectroscopic study, J. Eur. Ceram. Soc. 21 (2001) 2479-2485.

[90] S.A. Bernal, J.L. Provis, V. Rose, R. Mejía de Gutierrez, Evolution of binder structure in sodium silicate-activated slag-metakaolin blends, Cem. Concr. Compos. 33 (2011) 46-54

[91] A.P.d.S. Pereira, M.H.P.d. Silva, É.P. Lima Júnior, A.d.S. Paula, F.J. Tommasini, Processing and characterization of PET composites reinforced with geopolymer concrete waste, Mater. Res. 20 (2017) 411-420.

[92] M. Szechyńska-Hebda, J. Marczyk, C. Ziejewska, N. Hordyńska, J. Mikuła, M. Hebda, Neutral geopolymer foams reinforced with cellulose studied with the FT-Raman spectroscopy, IOP Conf. Series: Mater. Sci. Eng. 706 (2019) 012017.

[93] S. Kumar, R. Kumar, T.C. Alex, A. Bandopadhyay, S.P. Mehrotra, Influence of reactivity of fly ash on geopolymerisation, Adv. Appl. Ceram. 106 (2007) $120-127$.

[94] P.Z. Wang, R. Trettin, V. Rudert, Effect of fineness and particle size distribution of granulated blast-furnace slag on the hydraulic reactivity in cement systems, Adv Cem. Res. 17 (2005) 161-167.

[95] J. Schindelin, I. Arganda-Carreras, E. Frise, V. Kaynig, M. Longair, T. Pietzsch, S. Preibisch, C. Rueden, S. Saalfeld, B. Schmid, J.-Y. Tinevez, D.J. White, V. Hartenstein, K. Eliceiri, P. Tomancak, A. Cardona, Fiji: an open-source platform for biological-image analysis, Nat. Methods 9 (2012) 676-682.

[96] K.K. Aligizaki, Pore Structure of Cement-Based Materials: Testing, Interpretation and Requirements, CRS Press, 2005.

[97] G. Constantinides, K.S. Ravi Chandran, F.J. Ulm, K.J. Van Vliet, Grid indentation analysis of composite microstructure and mechanics: principles and validation, Mater. Sci. Eng. A 430 (2006) 189-202.

[98] J. Němecek, V. Smilauer, L. Kopecky, J. Německová, Nanoindentation of alkaliactivated Fly ash, Transp. Res. Rec. 2141 (2010) 36-40.

[99] V. Bewick, L. Cheek, J. Ball, Statistics review 9: one-way analysis of variance, Crit Care 8 (2004) 130.

[100] N.J. Salkind, Encyclopedia of Measurement and Statistics, SAGE Publications, Thousand Oaks, California, 2007.

[101] F. Lolli, H. Manzano, J.L. Provis, M.C. Bignozzi, E. Masoero, Atomistic simulations of Geopolymer models: the impact of disorder on structure and mechanics, ACS Appl. Mater. Interfaces 10 (2018) 22809-22820.

[102] J.E. Oh, P.J.M. Monteiro, S.S. Jun, S. Choi, S.M. Clark, The evolution of strength and crystalline phases for alkali-activated ground blast furnace slag and fly ashbased geopolymers, Cem. Concr. Res. 40 (2010) 189-196.

[103] J.J. Chen, L. Sorelli, M. Vandamme, F.-J. Ulm, G. Chanvillard, A coupled Nanoindentation/SEM-EDS study on low water/cement ratio Portland cement paste: evidence for C-S-H/Ca(OH)2 Nanocomposites, J. Am. Ceram. Soc. 93 (2010) 1484-1493.

[104] H.M. Jennings, J.J. Thomas, J.S. Gevrenov, G. Constantinides, F.-J. Ulm, A multitechnique investigation of the nanoporosity of cement paste, Cem. Concr. Res. 37 (2007) 329-336.

[105] J. Yang, D. Hou, Q. Ding, Structure, dynamics, and mechanical properties of crosslinked calcium Aluminosilicate hydrate: a molecular dynamics study, ACS Sustain. Chem. Eng. 6 (2018) 9403-9417.

[106] I. Lecomte, C. Henrist, M. Liégeois, F. Maseri, A. Rulmont, R. Cloots, (micro)structural comparison between geopolymers, alkali-activated slag cement and Portland cement, J. Eur. Ceram. Soc. 26 (2006) 3789-3797.

[107] I. García-Lodeiro, A. Fernández-Jiménez, A. Palomo, Variation in hybrid cements over time. Alkaline activation of fly ash-Portland cement blends, Cem. Concr. Res. 52 (2013) 112-122.

[108] I. García-Lodeiro, A. Fernández-Jiménez, A. Palomo, D.E. Macphee, Effect of calcium additions on N-A-S-H Cementitious gels, J. Am. Ceram. Soc. 93 (2010) 1934-1940. 